ISSN: 0514-7336

DOI: http://dx.doi.org/10.14201/zephyrus2018826592

\title{
LOS DISCOS DE ORO DEL MUSEO ARQUEOLÓGICO DE ASTURIAS: ALGUNAS OBSERVACIONES SOBRE LA ORFEBRERÍA PREHISTÓRICA
}

\section{The gold discs of the Archaeological Museum of Asturias: some observations on prehistoric goldsmithing}

José Javier Fernández Moreno*, Beatriz García Alonso**, Rodrigo Álvarez García *** y Miguel Ángel Fernández GonZÁlez ****

* D. G. Patrimonio Cultural-scyL. Monasterio de Prado, s/n. 47071 Valladolid. Correo-e: jjavier.fernandez@jcyl.es. ID ORCID: 0000-0002-6904-5237

** Museo Arqueológico de Asturias. C/ San Vicente, 3-5. 33003 Oviedo. Correo-e: beatriz.garciaalonso@asturias.org. ID ORCID: 0000-0002-7753-5308

*** Escuela de Ingeniería de Minas, Energía y Materiales. Cl De la Independencia, 13. 33004 Oviedo. Correo-e: alvarezrodrigo@uniovi.es.ID ORCID:0000-0002-2651-1103

**** Microprobe Electron Analisys-Univ. de Oviedo. Cl Julián Clavería, s/n. 33006 Oviedo. Correo-e: microsonda. oviedo@gmail.com.ID ORCID:0000-0002-3010-974x

Recepción: 15/1/2018; Revisión: 11/02/2018; Aceptación: 16/06/2018

Resumen: Se presenta un estudio detallado de dos discos de oro de procedencia desconocida que permanecen depositados desde mediados del s. xx en el Museo Arqueológico de Asturias. Pese a la abundante bibliografía sobre estas piezas, hasta el momento no se había realizado un análisis arqueométrico y arqueometalúrgico de las mismas. Los resultados permiten inferir observaciones interesantes acerca de su composición, manufactura y secuencia tecnológica de elaboración, así como sobre la posible procedencia del oro, confirmando, con los paralelos reconocidos para la decoración de estas placas, de una clara raigambre atlántica.

Los ejemplares de las Islas Británicas se asocian con inhumaciones campaniformes. Para los objetos en estudio se consideró una cronología más moderna dada la ausencia de evidencias similares en Asturias. Sin embargo, la reciente identificación de las típicas cerámicas en espacios de transformación de mineral de cobre en el territorio central asturiano posibilita una nueva consideración, reforzada con los más recientes hallazgos áureos de similar cronología en la Península Ibérica que se reconocen como parte del ajuar de inhumaciones campaniformes. Todos los argumentos refuerzan la propuesta de la existencia de redes de intercambio entre las Islas Británicas y el continente a lo largo de aquel periodo.

Palabras clave: Campaniforme; orfebrería en oro; discos solares; análisis FRX y EPMA.

AвSTRACT: We present a study of two gold discs of unknown origin that remain deposited since the midtwentieth century in the Archaeological Museum of Asturias. There is abundant bibliography on these pieces, although, to date, these have not been archaeometric or archeometallurgical studies. The results allow deducing interesting observations on their composition, manufacture and the technological sequence of elaboration, as well as on the possible origin of the gold, confirming, along with the parallels of the decoration of these disc, their Atlantic roots. 
The disks of the British Isles are associated with the burials of the Bell Beaker culture. For the objects under study, a more modern chronology was considered due to the absence of similar evidence in Asturias. The recent identification of these typical ceramics in spaces for transformation of the copper ores in the Asturian central territory makes it possible a new valuation, reinforced by the most recent gold findings, of similar chronology, in the Iberian Peninsula, which are recognized as burial furnishings of the Bell Beaker culture.

All these arguments reinforce the proposal on the existence of exchange networks between the British Islands and the continental mainland throughout this period.

Key words: Bell Beaker culture; goldsmith; sun discs; FRX and EPMA analysis.

\section{Introducción}

Trabajos habituales de conservación y mantenimiento de las colecciones del Museo Arqueológico de Oviedo posibilitaron acometer un análisis arqueométrico y una aproximación al estudio arqueometalúrgico de los dos discos perforados de oro que, de procedencia desconocida, se custodian en dicho centro $^{1}$. Las piezas carecían de este tipo de análisis, pese a haber sido objeto de numerosas referencias nacionales e internacionales, entre otras: Ruiz Gálvez (1979), Escortell (1982), Hernando (1983), Perea y Sánchez-Palencia (1995), Comendador (1997), Armbruster y Parreira (1993), Armbruster (2000), Cahill (2015) y de estudios específicos, singularmente

1 Queremos agradecer a la Dirección General de Patrimonio del Principado de Asturias -en la persona de su titular, O. Requejo- la autorización para la realización de los estudios que se presentan y su apoyo para realizarlos, así como al director del Museo Arqueológico de Asturias, I. García, por las gestiones y trámites para hacerlo posible. Asimismo, a M. Cahill, keeper of Irish Antiquities, del National Museum of Ireland, por su amabilidad en facilitarnos datos concretos sobre diversas piezas, así como referencias y distintas sugerencias para plantear y orientar nuestro estudio. A A. Gwilt, del National Museum Wales; a L. Brown, curator of Wiltshire Museum; a I. Perzia del Dpt. of Antiquities en el Ashmolean Museum of Art and Archaeology, por la información facilitada sobre las piezas que custodian en sus respectivos museos y colecciones. Al prof. G. Delibes de Castro, de la Univ. de Valladolid, por sus interesantes sugerencias y comentarios que han permitido mejorar el texto. También agradecemos la atención que nos prestaron J. M. Santos Martínez (Astorga, León), T. Legido (Ávila) y C. Gutiérrez Naves (Oviedo), orfebres y joyeros, por su asesoramiento para comprender y explicar buena parte de las peculiaridades técnicas que se han podido identificar en el estudio detallado de las piezas. Agradecemos sus explicaciones sobre los procesos actuales que, si no explican los antiguos, sí sirven para contrastar muchas de las cuestiones planteadas.

\begin{tabular}{|c|c|c|c|c|}
\hline $\begin{array}{c}\text { N. }^{\circ} \text { DE } \\
\text { INVENTARIO }\end{array}$ & $\begin{array}{c}\text { DIÁMETRO } \\
(\mathrm{cm})\end{array}$ & $\begin{array}{c}\text { GROSOR } \\
(\mathrm{cm})\end{array}$ & $\begin{array}{c}\text { PESO } \\
(\mathrm{g})\end{array}$ & $\begin{array}{c}\text { ÍNDICE DE SUPERFICIE } \\
\text { ESPECÍ́IICA (ISE) } \\
(\text { Perea, 1991) }\end{array}$ \\
\hline 3257 & 5,65 & 0,021 & 6,5 & 3,857 \\
\hline 3258 & 5,81 & 0,021 & 7,9 & 3,355 \\
\hline
\end{tabular}

Fig. 1. Medidas de los discos del Museo Arqueológico de Asturias.

por De Blas (1983, 1985, 1999, 2001 y 2011), quien se ha ocupado de ellos en diversas ocasiones en el marco de sus investigaciones sobre la metalurgia prehistórica asturiana. Constatada hace tiempo la falta de cualquier tipo de documentación sobre el ingreso en la colección del citado museo (De Blas, 1983: 128), las últimas pesquisas sirven para ratificar el hallazgo en el área occidental del Principado, y su ingreso en el museo a mediados del s. Xx, cuando se registra la primera referencia de las piezas (De Blas y López, 2001).

Por otra parte, aunque se trata de un hallazgo descontextualizado, la existencia de otras piezas similares en zonas próximas, tanto en el vecino territorio portugués como los muy abundantes de las Islas Británicas, así como el hallazgo en el mismo territorio de otros objetos áureos de cronología próxima, caso de un anillo de la Mata'l Casare (De Blas, 1990), suman argumentos para no descartar la presencia de este tipo de objetos en el centro de la cornisa cantábrica.

Los discos se conservan en muy buen estado, sin apenas roces ni deformaciones producidos por el uso o la inadecuada manipulación posterior ${ }^{2}$. Visualmente

2 Presentan una pátina uniforme que le da un color rojizo y de la que carece uno de los cuadrantes del disco n. ${ }^{\circ}$ 03257, quizás debido a una limpieza posterior a su descubrimiento, con el fin de comprobar la autenticidad del oro. Como afección asociada a la propia fabricación de las piezas se observan pequeńas fisuras propias del recocido y enfriamiento 


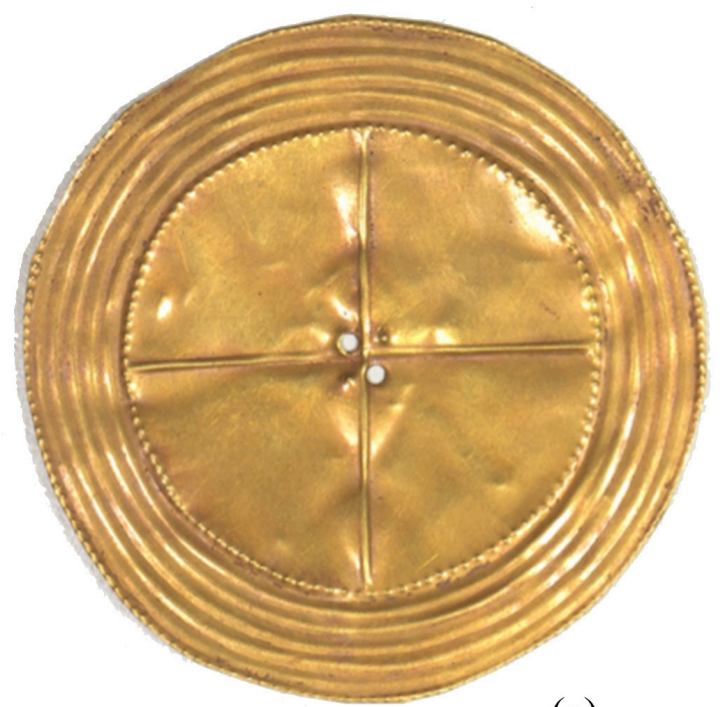

(a) 03258
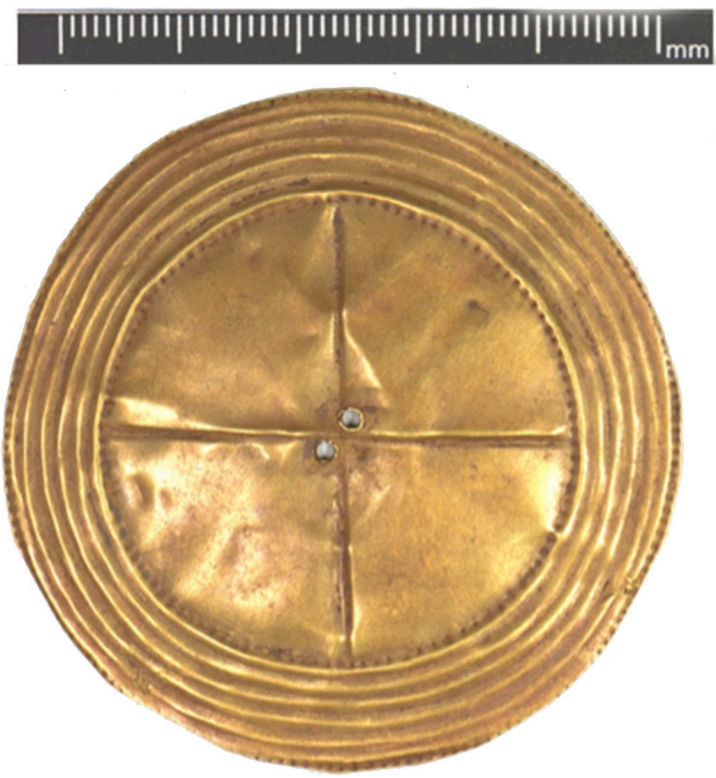

(c) 03258

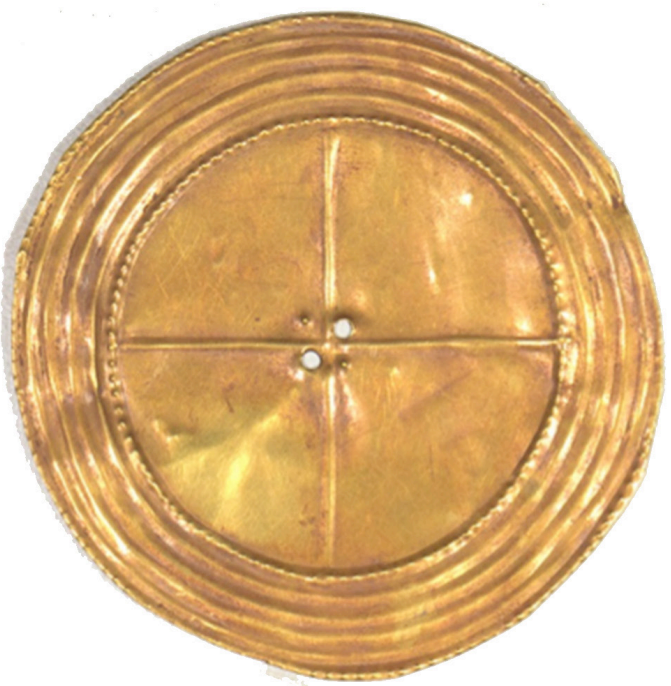

(b) 03257
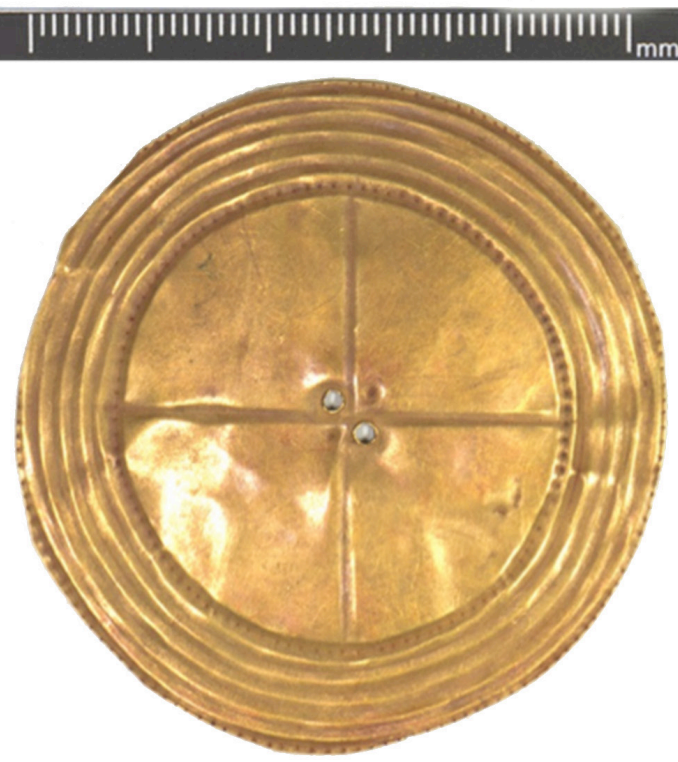

(d) 03257

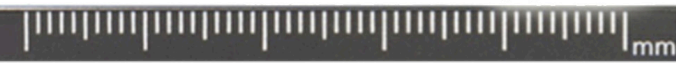

Fig. 2. Imagen de los discos: a-b) anversos de las piezas 03258 y 03257; $c$-d) reversos.

no se aprecian corrosiones parásitas pertenecientes a componentes secundarios de metal. Formalmente

del metal, así como defectos propios del proceso de decoración que en el disco n. 03258 evidencian grietas de entidad leve, visibles desde el anverso y reverso, coincidiendo con el punto central del cruciforme. Al tratarse de grietas antiguas y no presentar deformaciones recientes, no hace pensar en un riesgo relevante para el disco. Durante los años de conservación en son casi idénticos, aunque presentan ligeras diferencias (Fig. 1). De mediano tamaño, están decorados

el Museo Arqueológico de Asturias, se llevaron a cabo sendas copias por un orfebre, que obligadamente fueron realizadas mediante la ejecución de un molde de caucho sobre los originales. Este hecho, a juzgar por el estudio de las fotografías históricas de las piezas, no provocó ningún tipo de deformación o daño. 
en una de sus caras con un mismo motivo cruciforme, resaltado e inscrito en una serie de círculos concéntricos, también en relieve, lisos, a excepción de los dos exteriores que muestran un punteado rítmico y continuo. Ambos objetos tienen en su centro dos perforaciones que atraviesan la chapa, centradas y contrapuestas en los cuarterones divididos por el motivo cruciforme. Estas perforaciones debieron servir para sujetar o colgar cada disco -seguramente para coser la pieza a la indumentaria-, indistintamente de que tuvieran uso funcional -como botón- o de adorno (Fig. 2).

\section{Adscripción cronológica y cultural}

En la bibliografía más reciente, los discos del Museo de Oviedo son tratados por Ruiz-Gálvez (1979: 164-165, fig. 4, n.o 4), quien plantea su estudio a partir de su asociación con otras piezas como las lúnulas, para las que propugna un origen irlandés. Posteriormente, De Blas (1983: 128-130), manteniendo similares paralelos a las piezas, se decanta, dentro del contexto atlántico con el que indudablemente se asociarían, por una producción indígena, a partir de oro aluvial de la zona -Sánchez-Palencia (1983) considera esta técnica como la habitual para la etapa prerromana, siendo posteriormente contrastada su eficacia por Vázquez Varela (1995)-, conviniendo una cronología, derivada de la indudable asociación de las técnicas decorativas al contexto campaniforme, y, en el caso de las piezas que nos ocupan, con las especies más tardías.

En el mismo año se incluyen en un estudio de la orfebrería calcolítica peninsular (Hernando, 1983: 87, 113-114), refiriendo sus semejanzas con los discos del condado de Roscommon, en Coggalbeg, Irlanda. El estudio incluye las piezas en el tipo $2 \mathrm{~b}$ de 'discos o botones', interpretándose como adornos utilizados como joyas, para los que se propone un origen irlandés e inspiración centroeuropea, y una cronología que se asocia al fenómeno campaniforme, por lo que se estima que los de la Península Ibérica, como deriva de su llegada desde las Islas Británicas, se corresponderían con los momentos tardíos del Campaniforme e incluso en los primeros momentos de la Edad de la Bronce.

Una década después, en la exposición Arqueología del oro Astur, se reproducen ambos discos, describiéndose como dos láminas de revestimiento circulares con una sencilla decoración repujada de círculos concéntricos. Atribuidos también al ámbito campaniforme, son considerados como los vestigios más antiguos de la orfebrería asturiana, toda vez que el anillo procedente de La Cobertoria (De Blas, 1990) se asocia a una fase ligeramente más moderna (Perea y Sánchez-Palencia, 1995: 17-18).

Las piezas son de nuevo recogidas en el estudio de los inicios de la metalurgia en el no de la Península Ibérica (Comendador, 1997: 270 y ss.; n. ${ }^{\circ}$ inv. 195 a y b) incluyéndolos en el grupo de los adornos, si bien por las imprecisas circunstancias de su hallazgo plantea la posibilidad tanto de que correspondan a un escondrijo o depósito como a un ajuar funerario, lo que no ayuda a precisar su cronología que, en todo caso, y por el contexto de los hallazgos áureos del cuadrante noroccidental se encuadrarían entre la etapa calcolítica precampaniforme hasta el Bronce Medio. Aun cuando se valora -en algunos casos- la similitud de ciertas decoraciones repujadas con los motivos de las cerámicas campaniformes (Comendador, 1997: 435, 448, 454 y 458), la misma autora cuestiona la asociación de un tecnoestilo a una determinada y exclusiva etapa cronológico-cultural (Comendador, 1999: 30-33).

Posteriormente, en un amplio estudio de la metalurgia en las regiones de Asturias y Cantabria, los discos se adscriben, junto al referido anillo del dolmen de la Matal'l Casare, a la fase que se denomina de 'Desarrollo del Bronce Antiguo', en un momento inmediatamente posterior a las puntas Palmela, adscritas a la etapa final de la denominada 'Fase de Implantación' que abarcaría el Calcolítico y los inicios del Bronce Antiguo (De Blas, 1999: 47-57), matizando la asociación de este tipo de discos a materiales del ajuar campaniforme. Destacando su raigambre irlandesa asociada a una primitiva orfebrería campaniforme, se asignaron, una vez más, a una procedencia funeraria, probablemente como ajuar de un personaje destacado de los inicios de la Edad del 
Bronce (De Blas, 2011: 111). Más recientemente, esta vinculación ha sido de nuevo reseñada para el conjunto del anillo citado, los discos áureos y una desaparecida cinta o diadema; todos objetos de probable procedencia funeraria (De Blas y Rodríguez del Cueto, 2015: 175; De Blas y López Álvarez, 2001), a la que también se atribuyen los discos decorados con círculos concéntricos procedentes de Cabeceiras de Basto (López Cuevillas, 1955: 19; Armbruster y Parreira, 1993: fig. 76 y 77; Vilaça y Pinto, 2012: 17-18, fig. 9; Correia, 2013: fig. 12), asociados a una lúnula que se custodia en el Museo Arqueológico Nacional lisboeta. Las piezas fueron adquiridas en 1921 (Comendador, 1997: n. ${ }^{\circ}$ inv. 48a-c), lo que llevó a cuestionar en algún momento la unidad del conjunto, máxime por cuanto era la única documentada en la Península Ibérica (Contador, 1999: 22), si bien nuevos hallazgos confirman esta misma asociación en Irlanda (Kelly y Cahill, 2010; Armbruster y Comendador, 2015: 146-147) y refuerzan el carácter atlántico y asociado de ambos modelos.

Sin duda, fue la contrastada escasez de elementos campaniformes en el territorio asturiano la que cuestionó la adscripción de los discos a este momento, considerándose una atribución más tardía. En el ámbito atlántico no pocas de estas piezas, generalmente identificadas por pares, se documentan precisamente asociadas a inhumaciones individuales, con ajuares que evocan ese mismo fenómeno en las Islas Británicas. Tal es el caso de los discos procedentes de una inhumación ¿doble? con un vaso campaniforme con técnica mixta, un puñal de lengüeta y un brazal de arquero, aparecida en Mere Down -Wiltshire- o los cercanos del túmulo de Monkton Farleigh, descubiertos en 1947 y depositados en el mismo museo de Gran Bretaña (Waddell, 1998: 133-134, fig. 52)33. Más reciente fue el descubrimiento del ejemplar galés de Banc Tynddol,

3 Stourhead Collection, Wilshire Museum (http:// www.wiltshireheritagecollections.org.uk/wiltshiresites. asp? page $=$ selected place $\&$ mwsquery $=\% 7 \mathrm{BPlace} \% 20$ identity\%7D=\%7BMere\%20G6a\%7D; http://www.dailymail. co.uk/sciencetech/article-3136067/Stonehenge-s-sun-discrevealed-Rare-4-500-year-old-gold-decoration-grave-nearsacred-site-goes display.html\#ixzz3iPZ41mg4) [acceso: diciembre de 2017].

(C) Universidad de Salamanca
Cwmystwyth, también asociado a una inhumación campaniforme, en un antiguo asentamiento minero (Timberlake et al., 2004).

Si las asociaciones referidas apuntan a una atribución campaniforme, los esquemas decorativos parecen también insistir en dicha propuesta. Dos son los motivos que se reiteran, los círculos concéntricos y las cruces, bien lisos, bien asociados a otros en relieve, a modo de incisiones o puntos que se realizan con técnica de repujado por el reverso de la pieza. Los discos del Museo de Asturias ofrecen la combinación de todos ellos, con simplicidad de líneas, especialmente el motivo cruciforme o de aspa que queda inscrito en una serie de círculos concéntricos que rodean el exterior del disco. Atendiendo a la decoración, los discos se vienen agrupando en dos amplios bloques: aquellos que reproducen exclusivamente círculos concéntricos -p. e. Cabeceiras de Basto (Vilaça y Pinto, 2012); el de Banc Tynddol (Timberlake et al., 2004), o los irlandeses de Lough Gur, Co. Limerick; Cloyne, Co. Cork; Irlanda W269; o Ballyvourney, Co. Cork (Cahill, 2012: láms. 1 y 9)-; y los que destacan por la presencia de elementos cruciformes en su área central, con mayor o menor abigarramiento en los círculos periféricos que generalmente los delimitan -sería el caso, p. e., de los propios del Museo de Asturias; los irlandeses de Ballina, Co. Mayo; Ireland w270; Coggalbeg, Co. Roscommon (Cahill, 2012: lám. 2); o los dos que custodia el Museo de Wiltshire-. Al respecto, Mary Cahill (2015, 28-30; láms. 5-6) en su trabajo sobre el simbolismo astral de la joyería de los inicios de la Edad del Bronce establece un claro paralelismo, evidente, entre las decoraciones de este segundo grupo y las que se desarrollan en el fondo de las vasijas del campaniforme inciso y específicamente de los tipos Ciempozuelos, tanto irlandeses como del área central de la Península Ibérica, un planteamiento que ya había sido señalado por Hernando (1983: 129) para determinadas placas incisas de oro. Al respecto, cabría considerar la posibilidad de determinar la similitud de los discos del primero de los grupos con las decoraciones de los fondos, bases, de los campaniformes de estilo Internacional o Puntillado Geométrico que cuentan con motivos 
similares (Garrido, 2000: 201 y 2016), si bien, por desgracia, pese a lo evidente de la asociación, no contamos con una tipología de esquemas tan completa como la descrita para los incisos (Garrido, 2000: fig. 55).

Los más recientes hallazgos de cerámicas campaniformes de estilo Marítimo asociadas a estructuras externas de las propias explotaciones mineras de cobre de El Aramo (De Blas y Rodríguez, 2015: 168-170) posibilitan confirmar la existencia, en zonas próximas a la de la supuesta procedencia de los discos en estudio, de las cerámicas habituales a las que se asocian los botones perforados británicos antes referidos, y a facilitar, por tanto, la consideración 'campaniforme' de los botones asturianos, aun cuando es cierta la disociación de unos materiales y otros, como ocurre también entre los hallazgos del noroeste peninsular.

Por el contrario, en el interior peninsular se identifica un importante, aunque siempre escaso y singular, número de hallazgos de orfebrería áurea asociados mayoritariamente a cerámicas campaniformes, en mayor número con las incisas, en proporción al grupo dominante en este territorio. Sin olvidar tampoco que muchos de estos hallazgos corresponden a asociaciones no documentadas con la metodología deseable; sí coincide, en todos los casos, que se trata de piezas laminares conseguidas por batido. En la actualidad se han inventariado casi medio centenar de piezas procedentes de poco más de una docena de enclaves, principalmente en el área occidental, si bien su distribución alcanza todos los extremos de la Meseta (Garrido, 2000: 186-189). Entre estos hallazgos quisiéramos destacar las chapitas, dos también -a ellas acudiremos posteriormente-, del conjunto de procedencia desconocida de la localidad soriana de Villar del Campo (Delibes, 1978; Hernando, 1983: 125), y otras aparecidas con posterioridad al catálogo referido: las sortijas cubrededos -indistintamente de otra posible interpretación de uso-, de nuevo un par, de Tablada del Rudrón, en La Lora burgalesa (Campillo, 2004: 259 y ss.; Fitzpatrick et al., 2016: 37-40); o los más recientes y bien documentados del conjunto madrileño del Camino de las Yeseras -San Fernando de Henares, Madrid-, singularmente una diadema de placas y cuentas tubulares, recuperada en un espacio funerario (Blasco y Ríos, 2010). En suma, se dibuja una generalización de asociación de objetos de fabricación laminar, decorados o lisos, con contextos funerarios de adscripción campaniforme, tal como es común en la región atlántica, ámbito cultural en el que hay que incluir los botones asturianos (Fig. 3).

No es objeto de este trabajo insistir en la discusión o justificación de las interpretaciones simbólicas solares de estas decoraciones (Cahill, 2015: 30; Armbruster y Comendador, 2015: 147) de las que toman su denominación más genérica sun discs, ni en las asociadas al mito del viaje del Sol (Kaul, 2003: 37 y ss.), ni -pese a la sugerente coincidencia de la identificación por pares- con el de los 'divinos gemelos' al que se asocian, tanto en el Mediterráneo como en centro/norte de Europa a lo largo del II milenio a. C., ni en las distintas representaciones en discos identificados tanto en petroglifos como sobre objetos metálicos de bulto redondo, y que reproducen diversos motivos cruciformes como los identificados en los radios de las ruedas de los carros, incluso unos y otros asociados, como en el caso del carro solar danés de Trundholm (Kaul, 2003: fig. 1; kat. 11; Kristiansen y Larsson, 2006: 289-329).

Sí creemos poder insistir, en la medida de nuestras posibilidades, en lo referente a su funcionalidad. Aun cuando en ocasiones se les ha supuesto una finalidad como placas para recubrir botones $u$ otras piezas de material perecedero, más recientemente, se ha insistido en una utilización propia, bien como botones, bien como elementos decorativos, cosidos directamente a la vestimenta o al cabello, etc., propugnando una denominación más aséptica, 'discos planos'. La presencia de perforaciones en los discos referidos hace suponer una utilización autónoma, y las alejan de otros objetos que carecen de ellas y ofrecen distintas soluciones para su sujeción.

Las piezas destinadas a recubrir otro elemento requieren algún tipo de aditamento para su sujeción, a modo de pestańa, para lo que debieran alargar la parte visible con un pequeño reborde que, doblado, remataría sobre el objeto recubierto, por ejemplo, una placa áurea, posibilitando la sujeción del forro. Aun cuando pudiera ajustarse por presión, 


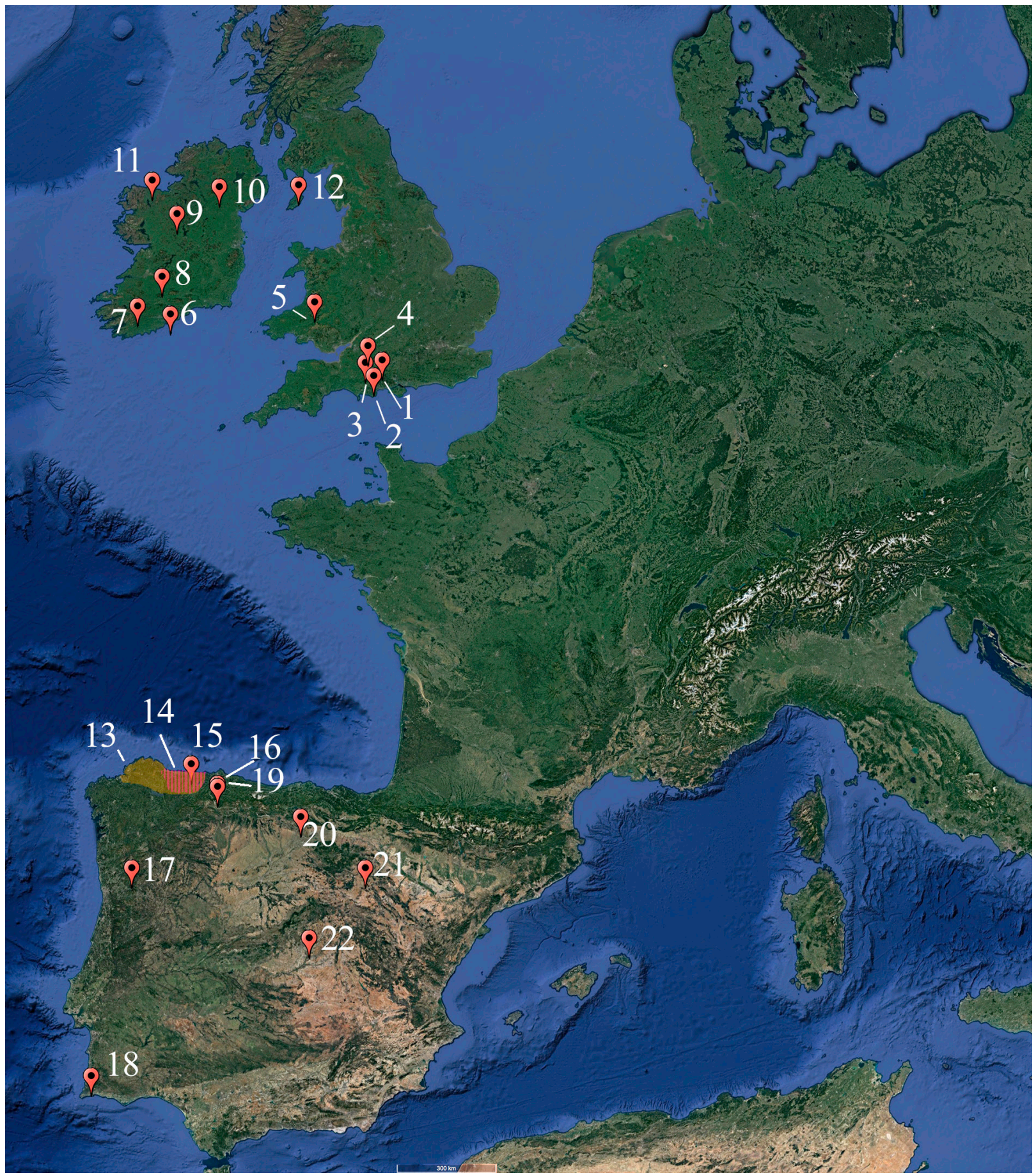

FIG. 3. Localización de los lugares citados en el texto: 1) Amesbury; 2) Boscombe; 3) Mere Down, Wiltshire; 4) Monkton Farleigh; 5) Cwmystwyth (Banc Tynddol); 6) Cloyne, Co. Cork; 7) Ballyvouney, Co. Cork; 8) Lough Gur, Co. Limerick; 9) Coggalberg, Condado de Roscommon; 10) Tedavnet; 11) Ballina Co. Mayo; 12) Kirk Andreas; 13) Fuentes de oro aluvial: parte de la costa norte de Galicia, norte de León y zona occidental de Asturias (amarillo); 14) Cuencas hidrográficas: Eo-Porcia-Navia-Esva (rosa); 15) Navelgas; 16) Minas del Aramo; 17) Cabeceiras de Basto; 18) Bensafrim, Lagos; 19) La Cobertoria; 20) Tablada del Rudrón; 21) Villar del Campo; 22) Camino de las Yeseras. 
sería casi seguro necesario contar con otros sistemas de sujeción de la placa metálica al elemento orgánico. Entre estas piezas a los que nos referimos, clasificadas por Hernando (1983: 125) como elementos para enganchar, destacan las denominadas 'plaquitas de recubrimiento', identificadas en el referido hallazgo soriano de Villar del Campo, en el reborde oriental de la Meseta Norte. Delibes (1977: 61, fig. 22; 1978) interpreta el conjunto como el correspondiente al ajuar de una inhumación campaniforme, destacando entre las ofrendas dos capsulas de oro, dos chapas que debieron recubrir sendos botones circulares u ovales, probablemente cónicos, tal vez de los típicos de perforación en ' $v$ ', que no son extraños en el interior peninsular (Garrido et al., 2005: 425). La ausencia de estos modelos ebúrneos en los ajuares asociados a la orfebrería irlandesa o británica y las relaciones que denuncian este tipo de piezas óseas, similares a las que se rastrean para alguno de los vasos de Villar del Campo (Delibes, 1978: 267-286), plantean un origen diferente al de los discos planos perforados y probablemente constituyan la “... evolución y difusión de modelos diferentes a partir de una misma tradición” (Hernando, 1983: 113), llegándose a considerar las chapas de revestimiento cónicas posteriores a los discos planos (Needham y Sheridan, 2014).

Otra solución de enganche o sujeción se identifica en los fragmentos de plaquetas que debieron configurar originariamente una diadema, recuperados junto a una de las inhumaciones del Camino de las Yeseras, Madrid (Liesau y Blasco, 2011-12: fig. 3). En este caso, las placas, de forma rectangular, presentan pequeñas perforaciones en los extremos que debieron servir para ajustar las piezas mediante tensores. Probablemente, en el caso de su unión a objetos óseos, la misma huella quedaría de la utilización de pequeños clavos o remaches, con seguridad suficientes para asegurar la unión de las piezas. Los discos que tratamos no presentan ni la típica curvatura ni huella de perforaciones para la sujeción, a excepción de las centrales. Algo similar ocurre en piezas de mayor tamaño, hasta doblar el diámetro de los botones asturianos, caso de los procedentes de Tedavnet (Cahill, 2015: 27), que muestran el mismo sistema de sujeción que el resto de las placas. Por el contrario, siquiera por ofrecer un ejemplo, aunque cronológicamente posterior y de dimensiones mayores a las que se comentan, el disco de Bensafrim sí tiene un reborde externo que supera el ámbito decorado y está doblado hacia el interior (Vilaça y Pinto, 2012: 15, figs. 2-3 y ss.).

La diferencia clara entre las chapas o cápsulas de recubrimiento y las piezas asturianas que nos ocupan o los denominados discos planos o botones a los que se adscriben es la existencia de sendas perforaciones centrales. A excepción de uno de los discos de Cabeceiras de Basto (Vilaça y Pinto, 2012: 17-18, fig. 9) que dispone de cuatro contrapuestas dos a dos, el resto de los ejemplares citados junto con los asturianos presentan mayoritariamente dos perforaciones contrapuestas en el centro de la pieza (p. e., Cahill, 2015) que servirían para asegurar la sujeción, quedando expuestos y a la vista, pudiendo cumplir la doble función de botón y adorno. No así cuando los agujeros aparecen en un extremo o lateral del disco, caso del procedente de Kirk Andreas, en la Isla de Man (Needham y Sheridan, 2014: 908, fig. 5a-c: b), o el denominado Ireland W266 (Cahill, 2015: lám. 3 superior derecha) -pese a combinar este sistema y el más tradicional de perforaciones centrales- que evidencian el interés, una vez cosidos, de facilitar su movimiento, bien al desplazarse el individuo portador de ellos, bien al ejecutar ritmos rituales, por ejemplo, de una danza.

Finalmente, tampoco hay evidencias concluyentes sobre si estas piezas fueron utilizadas a lo largo del tiempo o bien su función decorativa estuvo vinculada al ritual funerario. La ausencia de marcas de uso en los ejemplares asturianos, al igual que en otros muchos de los citados, lleva a suponer una utilización muy limitada, incluso inexistente, fuera del ritual de inhumación con el que se asocian la mayoría de los hallazgos. Por el contrario, el referido ejemplar de Wiltshire muestra un desplazamiento de los agujeros centrales, por su desgarro, hacia otros dos, equidistantes y centrados a su vez sobre uno de los brazos de la cruz, lo que hace suponer una larga utilización que contradice la opinión anterior, si bien es probable que el patrón de uso y 
finalidad de estas piezas no sea ni idéntico ni permanente a lo largo de tan amplio territorio y tiempo como en el que se reconocen.

\section{Análisis micrométricos}

Uno de los objetivos del presente estudio era el de profundizar en el conocimiento de estas piezas a partir de los análisis del material utilizado y de las huellas del proceso de fabricación, siguiendo propuestas ya definidas (Perea, 2010: 235 y ss. $)^{4}$.

Para conocer y determinar la composición del material empleado en la fabricación de estos objetos, hemos tenido la oportunidad de realizar, en los Servicios Científico Técnicos-scTs- de la Univ. de Oviedo, análisis de composición por fluorescencia de Rayos X -FRX- convencional y también mediante microsonda electrónica de barrido-EPMA-5 ${ }^{5}$.

4 Ha sido posible un estudio visual detallado y pormenorizado de las piezas por lupa binocular NIKON SMZ800 5x-16x y microscopio digital marca Dino-Lite, con salida UsB, de $5 \mathrm{Mp}, 0-150 \mathrm{x}$, con el que han sido realizadas las imágenes macro.

5 Se han realizado análisis por fluorescencia de Rayos $\mathrm{x}-\mathrm{FRX}$ - CONVENCIONAL -NITON XL3t-y también mediante microsonda electrónica-CAMECA Sx-100-. El empleo de la microsonda electrónica se estimó necesario al saturarse el detector del equipo de fluorescencia de Rayos x en concentraciones elevadas, de tal forma que la cuantificación de elementos mayores no resultaba fiable, aunque no es rutinario, el uso de esta técnica ya se ha validado (Pop et al., 2011) en el campo de los materiales arqueológicos. Las determinaciones mediante FRX se realizaron disponiendo el equipo directamente sobre los discos y excitando las muestras -en un área de unos $3 \mathrm{~mm}$ de diámetro- con radiación $\mathrm{x}$ generada a $50 \mathrm{kv}$ con una intensidad de corriente de 0,2 mA. El detector del equipo, de tipo si-pIN, está optimizado para metales de transición. La microsonda electrónica utilizada para determinar los resultados cuantitativos está equipada con 5 espectrómetros dispersores de longitud de onda -WDS-. La configuración establecida en este caso incluye un cristal LPET y un LLIF. Las condiciones analíticas aplicadas a la muestra fueron $20 \mathrm{kv}$ de voltaje de aceleración, $20 \mathrm{nA}$ de intensidad corriente y $5 \mu \mathrm{m}$ de diámetro transversal del haz electrónico. El tiempo de conteo sobre el pico de cada elemento fue establecido en 10_s. Las concentraciones finales fueron calculadas aplicando el método PAP de corrección
Los resultados obtenidos con la microsonda electrónica sobre un total de 9 análisis (Fig. 5) permiten una adecuada cuantificación de los constituyentes principales, que son $\mathrm{Au}$-contenido medio del 91,97\%-y Ag -6,57\%-. Del resto de elementos analizados, únicamente se han obtenido valores por encima de los límites de detección en $\mathrm{Fe}$-dos análisis que superan los $600 \mathrm{mg} / \mathrm{kg}$ - y Sn -en un análisis se supera el $0,1 \%$ en peso-. Por otra parte, es posible descartar la presencia de $\mathrm{Zn} / \mathrm{Pd} / \mathrm{Cd} / \mathrm{Ba} /$ $\mathrm{Pt}$ y Bi. Finalmente, $\mathrm{Cu} / \mathrm{Sn}$ y $\mathrm{Pb}$ no cuentan con medidas válidas -siempre aparecen por debajo del límite de detección-, pero sus lecturas no son nulas, por lo que su presencia en pequeñas cantidades, tal y como se había deducido mediante fluorescencia de Rayos x, parece confirmarse.

Por tanto, se trataría de un oro nativo de procedencia aluvial como es habitual entre los primeros hallazgos de orfebrería peninsular, pudiéndose incluir en la caracterización del tipo (s) según la clasificación ya tradicional (Perea, 1991: 31 y referencia a la de Hartmann, 1982: fig. 3, diagrama 1). En este tipo de mineralizaciones las partículas de oro están generalmente asociadas a $\mathrm{Ag}, \mathrm{Cu}, \mathrm{Fe}$ y otras impurezas, siendo habitual el contenido de Ag entre un 5 y un $15 \%$ y el $\mathrm{Cu}$ entre un 0,10 y un $20 \%$. Aunque no hay coincidencia plena en la distinción de una aleación a partir de la presencia de determinados elementos, se viene estimando tal consideración cuando los porcentajes de $\mathrm{Ag}$ y $\mathrm{Cu}$ superan porcentajes de 25 y 1 respectivamente (Montero y Rovira, 1991: 10), o bien cuando este último rebasa

del efecto matriz. Las mediciones se tomaron del anverso de las piezas, en zonas elegidas al azar. Se buscaban las zonas pulidas y sin presencia de suciedad o alteraciones, ya que la microsonda mide en superficie y no en profundidad, por lo que si hubiera oxidación de algún tipo la detectaría y falsificaría en un porcentaje mínimo el resultado. En cualquier caso, las distintas mediciones ofrecen resultados muy similares por lo que hay que deducir que, en principio, su elección no condiciona los datos obtenidos (Fig. 4). Los resultados de la FRX se van a considerar en este trabajo únicamente de forma cualitativa; así, cabría apuntar como rasgo más destacado una muy elevada relación $\mathrm{Au} / \mathrm{Ag}$ - por encima de 10:1- y contenidos detectables, en el rango de elementos traza, de $\mathrm{Cu}$ (unos $500 \mathrm{mg} / \mathrm{kg}$ de media), Pb -sobre 700 $\mathrm{mg} / \mathrm{kg}-$ y Sn $-900 \mathrm{mg} / \mathrm{kg}-$. 
74 J. J. Fernández, B. García, R. Álvarez y M. Á. Fernández / Los discos de oro del Museo Arqueológico de Asturias...
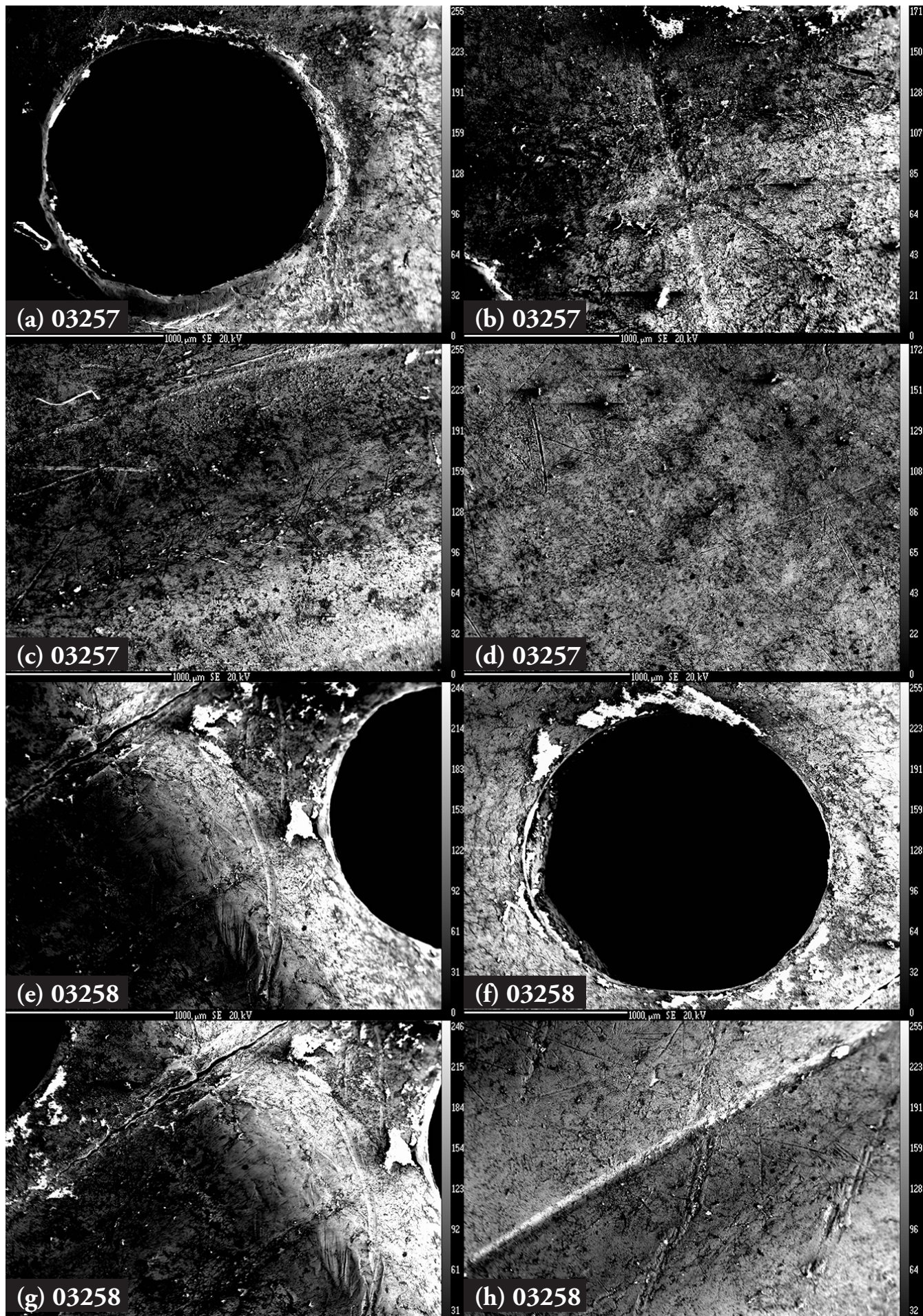

FIG. 4. Imágenes de algunas áreas analizadas mediante microsonda electrónica. Diferentes zonas de los anversos: a) orificio en el disco 03257; b-d) centro del disco 03257; e) centro del cruciforme del disco 03257; f) orificio del disco 03258; g) centro del cruciforme del disco 03258 y h) uno de los brazos del cruciforme del disco 03257. 


\begin{tabular}{|c|c|c|c|c|c|c|c|c|c|c|c|c|}
\hline Elemento & $\mathrm{Fe}$ & $\mathrm{Cu}$ & $\mathrm{Zn}$ & $\mathbf{A g}$ & $\mathrm{Pd}$ & $\mathrm{Cd}$ & Sn & $\mathrm{Ba}$ & $\mathrm{Pt}$ & $\mathrm{Au}$ & $\mathrm{Pb}$ & $\mathrm{Bi}$ \\
\hline Limite de detección & 0,0600 & 0,0700 & 0,0900 & 0,1300 & 0,1400 & 0,1500 & 0,1000 & 0,0500 & 0,3000 & 0,4000 & 0,2800 & 0,4000 \\
\hline \multirow{3}{*}{ Disco 03257} & 0,1019 & 0,0391 & 0,0000 & 6,9559 & 0,0000 & 0,0000 & 0,0384 & 0,0000 & 0,0000 & 93,1118 & 0,0050 & 0,0000 \\
\hline & 0,0445 & 0,0025 & 0,0000 & 5,0771 & 0,0000 & 0,0000 & 0,0761 & 0,0000 & 0,0000 & 92,8886 & 0,0623 & 0,0000 \\
\hline & 0,0070 & 0,0418 & 0,0000 & 7,9966 & 0,0000 & 0,0000 & 0,0000 & 0,0000 & 0,0000 & 91,2417 & 0,0357 & 0,0000 \\
\hline \multirow{5}{*}{ Disco 03258} & 0,0191 & 0,0327 & 0,0000 & 6,4091 & 0,0000 & 0,0000 & 0,0000 & 0,0000 & 0,0000 & 93,2218 & 0,0210 & 0,0000 \\
\hline & 0,0352 & 0,0479 & 0,0000 & 6,7924 & 0,0000 & 0,0000 & 0,0000 & 0,0000 & 0,0000 & 92,4253 & 0,0000 & 0,0000 \\
\hline & 0,0272 & 0,0545 & 0,0000 & 6,9352 & 0,0000 & 0,0000 & 0,0000 & 0,0000 & 0,0000 & 91,8687 & 0,0404 & 0,0058 \\
\hline & 0,0780 & 0,0374 & 0,0000 & 7,2247 & 0,0000 & 0,0000 & 0,1301 & 0,0105 & 0,0000 & 88,5696 & 0,0003 & 0,0000 \\
\hline & 0,0215 & 0,0579 & 0,0000 & 5,2219 & 0,0000 & 0,0000 & 0,0024 & 0,0000 & 0,0000 & 92,4366 & 0,1035 & 0,0000 \\
\hline Media & 0,0418 & 0,0392 & 0,0000 & 6,5766 & 0,0000 & 0,0000 & 0,0309 & 0,0013 & 0,0000 & 91,9705 & 0,0335 & 0,0007 \\
\hline Máximo & 0,1019 & 0,0579 & 0,0000 & 7,9966 & 0,0000 & 0,0000 & 0,1301 & 0,0105 & 0,0000 & 93,2218 & 0,1035 & 0,0058 \\
\hline Mínimo & 0,0070 & 0,0025 & 0,0000 & 5,0771 & 0,0000 & 0,0000 & 0,0000 & 0,0000 & 0,0000 & 88,5696 & 0,0000 & 0,0000 \\
\hline Desviación Estándar & 0,0323 & 0,0171 & 0,0000 & 0,9905 & 0,0000 & 0,0000 & 0,0487 & 0,0037 & 0,0000 & 1,5233 & 0,0358 & 0,0021 \\
\hline
\end{tabular}

FIG. 5. Resultados de los elementos cuantitativos detectados; todos los datos se expresan en \% en peso; se señalan en rojo las medidas realizadas por debajo del límite de detección de la técnica.

el 2,5\% (Bandera et al., 2010: 52). La presencia del estaño en una proporción de décimas o milésimas se atribuye a la casiterita de los oros de tipo aluvial (Tylecote, 1970: 23).

La ausencia en los análisis de elementos del grupo del platino - $\mathrm{Pt} / \mathrm{Pd} / \mathrm{Ir}$ - descarta un origen ligado a complejos de rocas ígneas ultrabásicas y refuerza la hipótesis de un origen ibérico. La presencia de un promedio del 6,57\% en $\mathrm{Ag}$ con trazas de $\mathrm{Cu}$ resulta demasiado genérica y tampoco permite desechar ninguno de los tipos de mineralización primaria -hidrotermales, fracturas rellenas de cuarzo con oro, intrusión-hosted, etc.-. A su vez, el origen de cualquier oro aluvial debe buscarse en una mineralización primaria dentro de la cuenca hidrográfica del río en cuyo curso aparece el propio oro aluvial: es sabido que la huella geoquímica del oro aluvial refleja la mineralogía del área fuente (Chapman et al., 2002).

En la Península Ibérica se han identificado importantes zonas auríferas, dando cuenta de esta riqueza el hecho de que España, en los primeros años del presente siglo, fuera el primer productor de oro en el entorno de los países de la Unión Europea (Perea et al., 2003: 4). Las posibles fuentes de oro aluvial se sitúan en el noroeste, en el cuadrante que configuran las actuales tierras del $\mathrm{N}$ de León y el o de Asturias y Galicia, a excepción del extremo más occidental a partir de una hipotética línea que uniría La Coruña y Santiago (Liesau y Blasco, 201112: fig. 1).
Dado que el hallazgo de las piezas del museo ovetense se situaría, como se ha referido, en el área occidental de Asturias, cabría localizar el origen del oro en la comarca Eo-Navia, donde existen cinco cuencas hidrográficas, todas ellas con algún indicio aurífero, sea de mayor o menor importancia. De o-E serían: Eo-Porcía-Navia-Negro-Esva. Algunas de las mineralizaciones auríferas de estas cuencas han sido objeto de detallados estudios mineralógicos y geoquímicos (Álvarez, 2003; Arias et al., 1993 y 1997; Villa et al., 1993 y García-Rodríguez et al., $1991)^{6}$, cuyo contenido excede el alcance de este documento al tratarse, en todos los casos, de estudios sobre mineralizaciones primarias. En cualquier caso, únicamente el oro aluvial del sector de Navelgas -cuenca del Esva- está razonablemente documentado, no permitiendo este dato por sí solo $-99,9 \%$ de $\mathrm{Au}$ - realizar apreciaciones consistentes. Ahora bien, la presencia de Sn lleva a considerar la hipótesis de una procedencia, en caso de ser local, más occidental (Comendador, 1997: 307 y 310), en tierras gallegas -probablemente del interior orensano- o del límite de estas con la zona del norte de León, toda vez que en ninguna de las mineralizaciones asturianas conocidas el oro aparece asociado a $\mathrm{Sn}$, y la única identificación de $\mathrm{Sn}$ asturiano, en Boal, en la cuenca del Navia, no cuenta con presencia conocida de oro.

6 También cf. Rodríguez Terente, L. M.: Las mineralizaciones auriferas de la granodiorita de Salave (Tapia de Casariego, Asturias). Tesis doctoral inédita presentada en 2007 en la Univ. de Oviedo. 
Los elevados porcentajes de Au son habituales en las piezas de estructura laminar que caracterizan el 'Periodo I, Inicial' adscrito al Calcolítico-Bronce Antiguo peninsular (Perea et al., 2010: 14 y 31) y así se refleja, por ejemplo, en los últimos estudios, caso de los del Camino de las Yeseras, que ofrecen mediciones que no difieren de las que se presentan, con porcentajes de Au entre 91 y $95 \%$ y de $\mathrm{Ag}$ del 5 y $7 \%$, contando con la identificación, en tres cuentas tubulares que fueron analizadas por el departamento del Museo del Louvre, de porcentajes de $\mathrm{Cu}$ entre 0,02 y 0,05\% (Liseau y Blasco, 2011-12: 215), si bien desconocemos la presencia de otros oligoelementos y, en su caso, la proporción de los mismos.

Lo cierto es que hay una ausencia importante de estudios de las mineralizaciones (Armbruster et al., 2004: 185; Blasco y Ríos, 2010: 366) y, por otra parte, de la difusión de los resultados completos de los análisis realizados a las piezas, específicamente de los oligoelementos que acompañan a los componentes principales y que son los que posibilitan identificar la procedencia de los minerales e incluso llegar a singularizar posibles 'talleres' o agrupaciones. En este sentido, parece necesario, además, profundizar en las analíticas de isótopos que posibilitan concretar relaciones con una alta fiabilidad, pese al necesario contraste de la metodología (p. e., Pernicka, 2014; Wood et al., 2017). En estudios recientes, sobre medio centenar de objetos de orfebrería de oro del Calcolítico y Bronce Antiguo de Irlanda, las signaturas isotópicas de plomo apuntan a una más que probable procedencia del metal de los depósitos aluviales del suroeste de Gran Bretaña (Standish et al., 2015), aun cuando con anterioridad, tanto para estas piezas como muchas de las halladas en Gran Bretaña, se había propugnado una procedencia común, de la mina de Ross Island (Gibson, 2013: 77). En todo caso, parece suficientemente confirmada la relación entre distintos territorios ya en las primeras etapas de la Edad del Bronce, tanto entre las cercanas Islas Británicas con el continente, como demuestran distintos análisis de piezas localizadas - p. e., en el centro de Alemania (Ehser et al., 2011: 904-908)-, como de aquellas con el territorio peninsular (Comendador $e t$ al., 2014: 287 y ss.). Del mismo modo, los análisis mineralógicos de los puñales de cobre depositados en la tumba del arquero de Amesbury, próxima al conjunto de Stonehenge, les atribuyen un origen peninsular, y muy probablemente del área asturiana (Needham, 2013), al igual que otros elementos del ajuar de este enterramiento y el próximo del arquero de Boscombe, e, incluso, los estudios antropológicos de los inhumados permiten confirmar a Bretaña como uno de los nodos de una amplia red de intercambio entre el continente y las islas, con seguridad desde el inicio de la segunda mitad del III milenio a. C. (Fitzpatrick, 2013).

Se ha planteado, acertadamente, que, en la fachada atlántica que discurre entre el estuario lisboeta y en la región bretona, la coincidencia en la distribución de cerámicas campaniformes y de determinados hallazgos metálicos solo se justifica por un intercambio marítimo que explicaría los amplios vacíos existentes entre los hallazgos puntuales (De Blas y Rodríguez, 2015: 170-171). En este contexto se explica la presencia de las cerámicas campaniformes de El Aramo como elementos de importación -al igual que los escasos objetos de oro del actual territorio asturiano- vinculados a la élite asociada a la explotación de mineral, fuera esta de origen autóctono o no (De Blas y Rodríguez, 2015: 173-175); reflejando lo que parece, en una clara simetría con el enterramiento del arquero de Amesbury antes referido, la posibilidad de que los personajes inhumados con este tipo de piezas metálicas y cerámicas de prestigio (Blasco y Ríos, 2010) no formaran parte de los grupos locales. Fuera de una forma u otra, la amplia distribución de las piezas áureas y otros objetos alóctonos y su asociación a un mismo tipo cerámico solo se explica por la existencia de complejas redes de intercambio que alcanzan el interior peninsular (Fitzpatrick et al., 2016).

Por tanto, desde los resultados de los análisis micrométricos, a la luz de los datos disponibles, es improbable concretar la procedencia del oro de los discos del Museo Arqueológico de Asturias por cuanto es imprescindible disponer de un número mayor de estudios geoquímicos y de elementos traza, tanto de los útiles como de la composición de los placeres, y singularmente de la caracterización 
isotópica de los mismos. Por los datos disponibles y el conocimiento actual de las distintas mineralizaciones es improbable atribuirlo a una procedencia local. Como hipótesis, se puede situar el origen más próximo en el entorno de los límites de las actuales provincias de León y Orense, pese a la ausencia de yacimientos prehistóricos en los principales ríos auríferos de la zona (Sánchez-Palencia et al., 1996: 10). Por ello no debiera extrañar -por los mismos criterios- que la procedencia del oro de estos discos se localizara en el sudoeste de Gran Bretaña. Más probable parece esta última atribución por cuanto es en aquel territorio, y específicamente en el irlandés, donde se sitúa el origen de este tipo de objetos. Los contactos entre las poblaciones insulares y las continentales están suficientemente contrastados en aquellos momentos, así como el carácter exótico de las piezas áureas y los vasos campaniformes marítimos asturianos, por lo que parece probable atribuir su presencia a intercambios demandados por una élite probablemente surgida con el desarrollo de las explotaciones mineras como las de El Aramo.

\section{Técnica y proceso de fabricación}

En el sector occidental de la Península Ibérica, los vestigios más antiguos del trabajo del oro atestiguan una técnica sencilla mediante batido para la realización de finas láminas o elementos simples a partir del forjado de alambres (Armbruster, 2000: 190), cuestionándose la aparición de técnicas más complejas, como la soldadura o la cera perdida, hasta la etapa castreńa (Perea y Sánchez Palencia, 1995a: 17 y 48), aun cuando se ha planteado una mayor antigüedad de las más complejas (Comendador, 1997: 398-401). Los análisis metalográficos vienen a confirmar que desde las primeras etapas la cadena operativa es repetitiva, desde el simple fundido y forja en frío hasta la que ańade el recocido y sucesiva forja (Rovira, 2004: 20).

En el caso de los botones asturianos, la técnica de fabricación se estudia siguiendo los procesos reconocidos, y con la observación detallada y directa de las huellas encontradas en la superficie de los objetos. De este modo, se clasifica el proceso tecnológico en los siguientes estadios de fabricación, según el orden en el que fueron llevados a cabo:

\subsection{Fundición y eliminación de impurezas}

Aun cuando se considera suficiente el martillado de las pepitas de oro nativo para la fabricación de sencillos adornos, lo cierto es que para la fabricación de objetos se precisa una mínima pero necesaria preparación de la materia prima (Comendador, 1997: 399-400; 1999: 30-32; Reboredo, 2000: 75): la fusión de diversas pepitas hasta conseguir la cantidad de material suficiente para la fabricación del objeto. La fundición de las pepitas de oro en un crisol no suponía ningún problema desde la segunda mitad del III milenio a. C. Sin ser una técnica generalizada en todos los territorios, sí que existen evidencias más antiguas que la atestiguan, por lo que no es necesario insistir en ello. La pureza del oro o su aleación con otros metales puede deberse a la propia mineralización o al interés del artesano por conseguir un producto con determinadas características para su manipulación o configuración final. Este proceso inicial no deja huella en la propia pieza. Por ello, y debido a la composición metalográfica similar de ambos discos, la única consideración que cabe resaltar es la de que fueron obtenidos por la fundición de oro aluvial de una misma procedencia y con la misma técnica.

La observación directa de las piezas determina que en la superficie no se aprecian puntos de oxidación propios de elementos menos nobles como el cobre o la plata, y el tono general responde a un amarillo que se torna rojizo en algunas zonas de la superficie y que, como se aprecia en el anverso del disco 03257 (Fig. 6a-b), parece corresponder a restos de elementos terrosos de granulometría muy fina, depositados en superficie y que se eliminan con facilidad. En algún caso, aparecen incluso huellas en superficie, por acumulación de estos restos, que parecen seguir un patrón definido que por el momento no podemos explicar (Fig. 6c-d). Hemos de suponer que estos depósitos son posteriores a la 

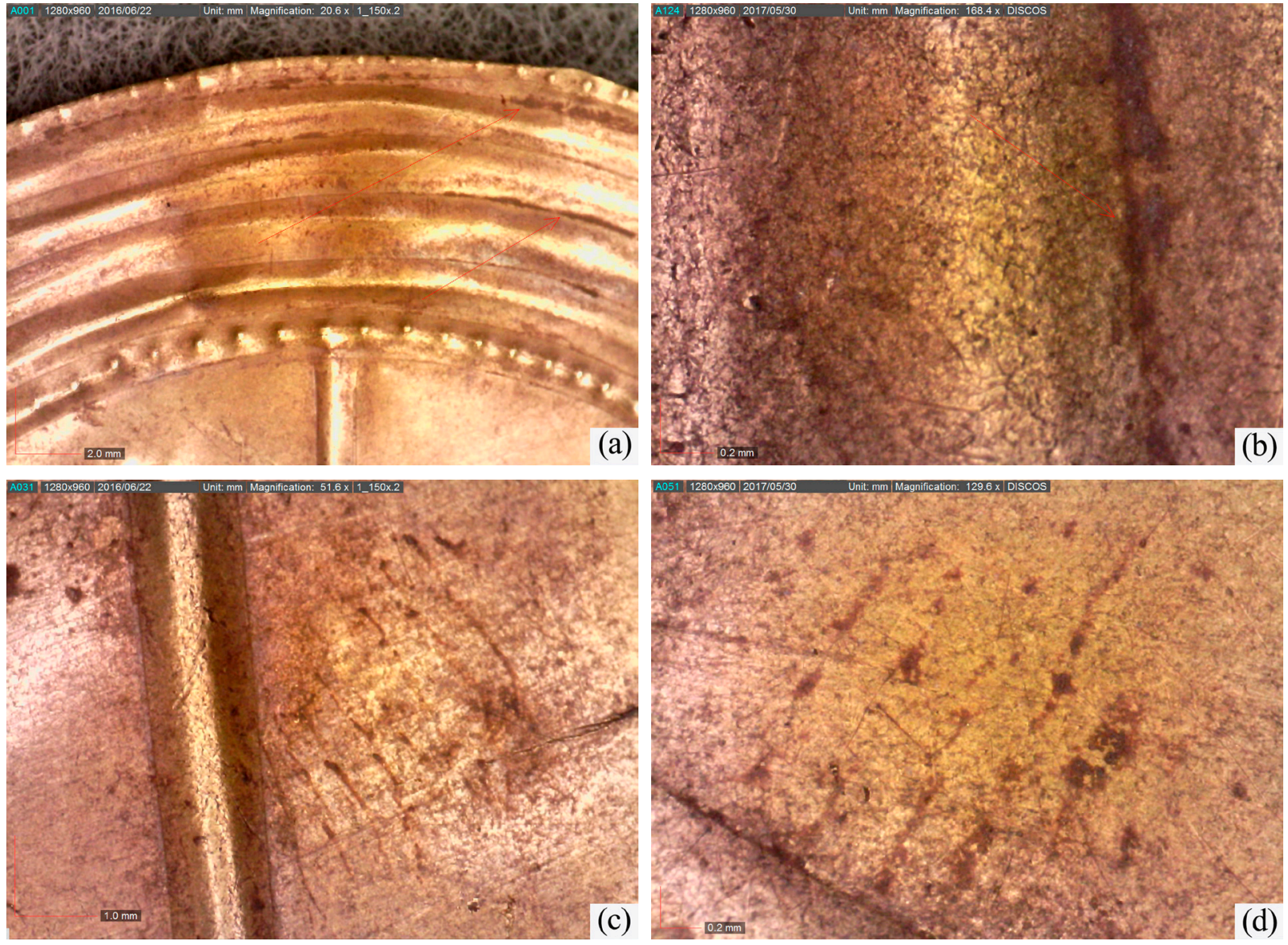

Fig. 6. Detalles del disco 03257: a) acumulación de restos terrosos en los círculos exteriores (aum.: 20,6x); b) acumulación de restos terrosos en el cruciforme (aum.: 168,4x); c-d) huellas de un patrón regular sobre la superficie del disco (aum.: 51,6x y 124,6x respectivamente).

fabricación de la pieza, toda vez que la superficie, como veremos, fue pulida.

\subsection{Conformación de la pieza}

Un indicador para conocer la técnica empleada es el denominado 'índice de superficie específica' -ISE- o 'índice de aprovechamiento del metal' (Perea, 1991: 37). En la fórmula que lo define, el resultado encuadra el ise de los discos del Museo de Oviedo (Fig. 1) en un grado medio ${ }^{7}$, característico de piezas

Perea (1991) enmarca el índice de aprovechamiento medio del oro -ISE- entre 3,54 y 10 unidades, correspondiendo los índices altos entre 14,6 y 43 unidades. El desvío del resultado del segundo de los discos es inapreciable, realizadas mediante lámina batida. Las láminas repujadas suelen tener índices de aprovechamiento menores y grosores más finos, por lo que los discos deben corresponder, técnicamente, a una fase inicial.

El proceso de trabajo se inicia con la extracción del botón de fundición del fondo del crisol, siendo extendido mediante batido por martilleado, reconocible por determinadas huellas en el anverso: solapamientos y pinzamientos del metal de escasa entidad (Fig. 7). Además, el espesor de los discos, $0,21 \mathrm{~mm}$, confirmaría este proceso por cuanto no se consideran factibles espesores inferiores a $1 \mathrm{~mm}$ para coladas en molde.

considerando que las franjas resultantes son promedio de las mediaciones realizadas, por lo que la clasificación debe ser idéntica en ambos: índice medio/bajo. 

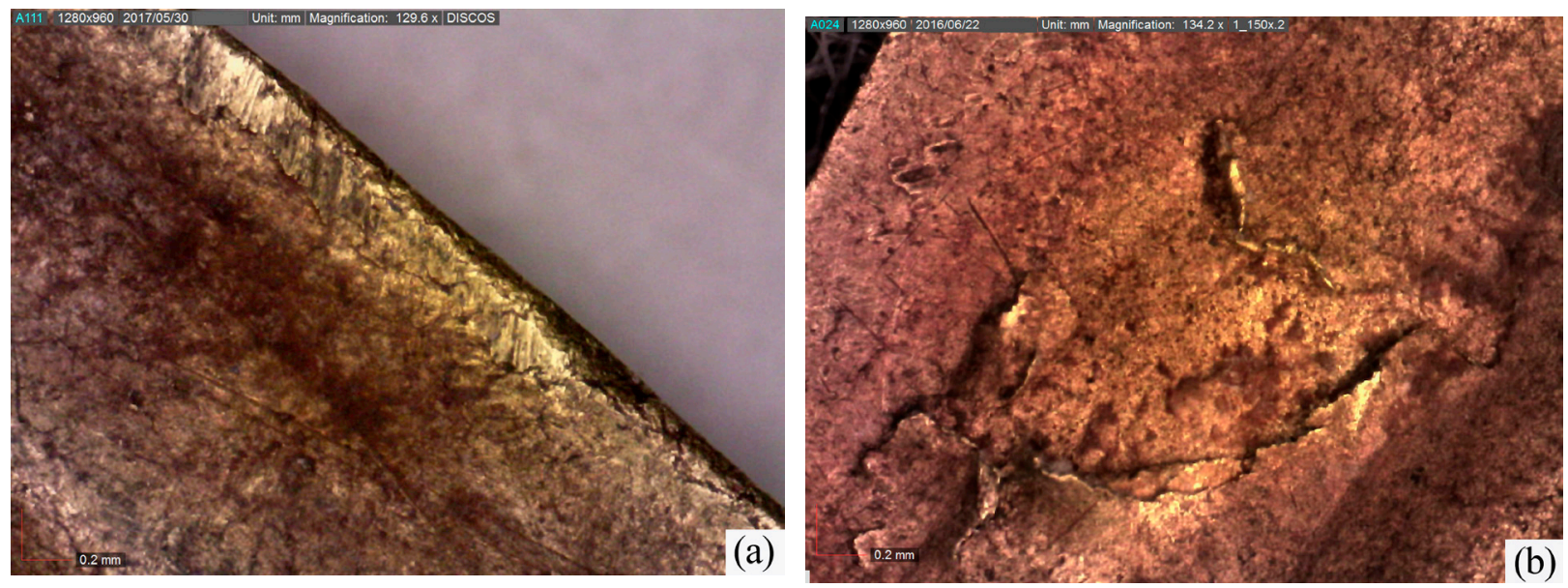

FIG. 7. Solapamientos en el metal producto del batido imperfecto en el reverso de: a) el disco 03257 (aum.: 129, 6x); b) el disco 03258 (aum. 134,2x).

El éxito en la extensión de la lámina por martilleado requiere de distintos medios, técnicas y procesos (Armbruster, 2000: 91-94; 116-117): de un lado, la sujeción de la pieza, máxime cuando se trata de objetos pequeños que hay que mover continuamente para repartir la presión de forma proporcional a toda la superficie; y, de otro, realizarlo sobre una superficie adecuada que, siendo dura, absorba los impactos, repartiendo las tensiones y soportando el calor del objeto. Son escasos los yunques de piedra identificados en el Calcolítico y la Edad del Bronce (Armbruster, 2001: citado en Armbruster et al., 2004: 181) y tampoco son habituales en periodos inmediatamente posteriores (Armbruster, 2000: 4954). Se ha señalado la dificultad para reconocerlos, e incluso su más que probable amortización, como muchos de los utensilios utilizados por los orfebres, que ajustarían sus equipos reaprovechando el material empleado (Perea, 2010: 249-251).

Para el martilleado, Perea (1991) propugna el uso de útiles perecederos y blandos, bien de madera o cuerna, aun cuando no hay que desechar otros, caso de algún útil pulimentado. Su identificación solo puede intentarse a partir de las improntas dejadas en la superficie, si bien estas huellas tienden a enmascararse por el posterior proceso de pulimento.
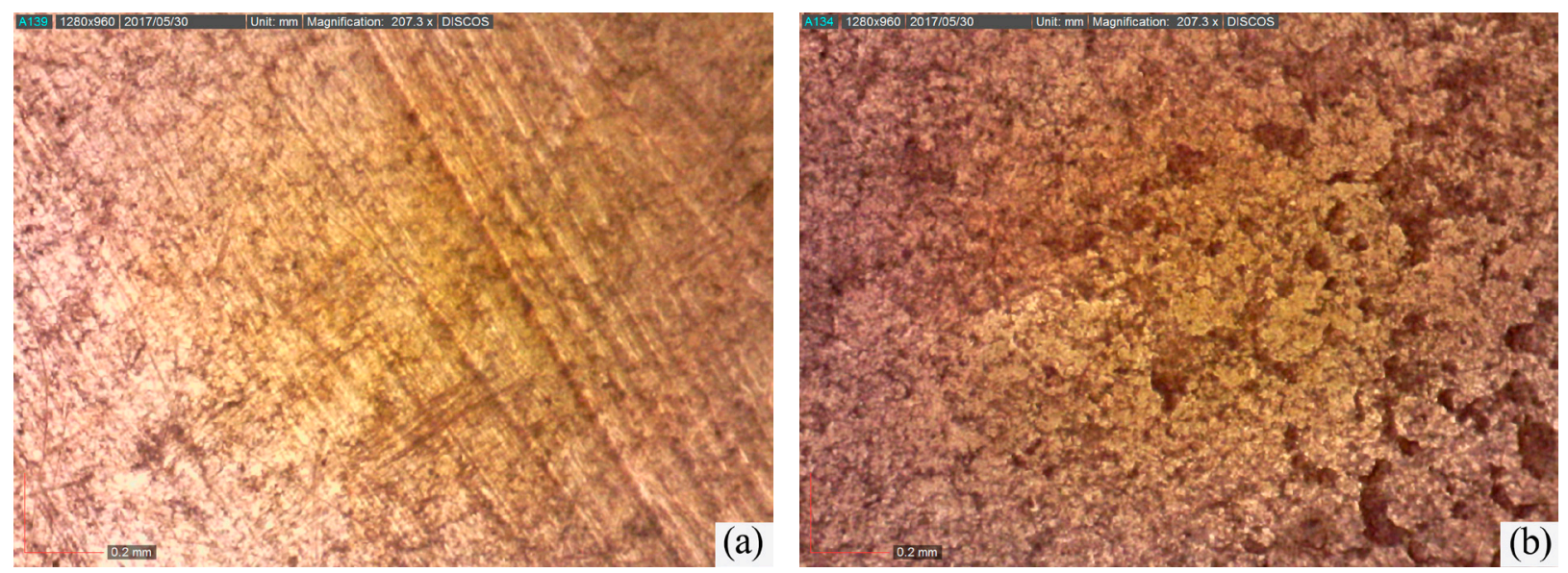

FIG. 8. Huellas en la superficie de los discos: a) huellas de pulido en el anverso (aum.: 207,3x); b) huellas del proceso de fabricación en el reverso (aum.: 207,3x). 


\subsection{Bruñido de las superficies}

Una vez conformada la lámina, con el grosor deseado, se procede al bruñido de la superficie. El pulido en este caso se realiza exclusivamente sobre el anverso de los discos. Bajo la lupa binocular se observan huellas y se aprecia un brillo no especular, sino matizado. El reverso de las piezas, pese a la finura de su acabado, no presenta huellas que evidencien bruñido y carece del reflejo característico presente en la cara decorada (Fig. 8), sin que se aprecien, tampoco, otras huellas atribuidas al uso de la pieza.

\section{Técnica y proceso de la decoración}

Si bien el proceso de fabricación de las láminas no aporta singularidad respecto a otras piezas conocidas, el de la realización de la decoración permite identificar un patrón específico para los discos del Museo de Asturias.
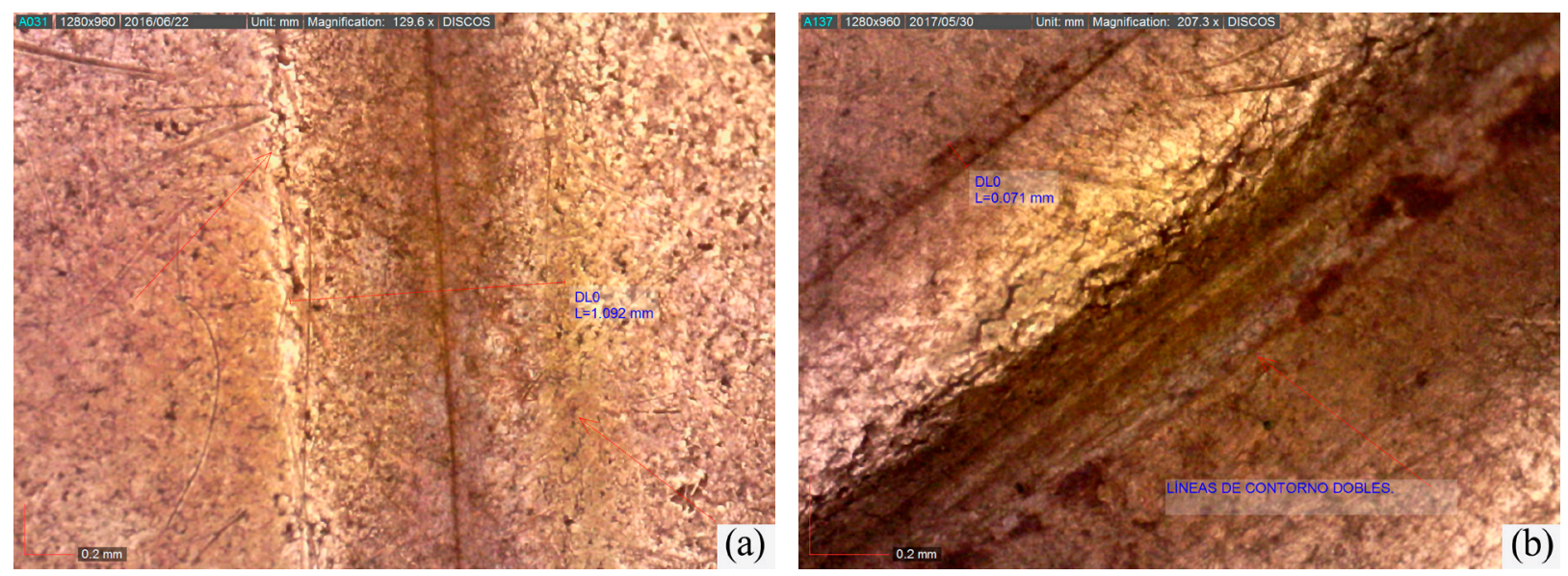

FIG. 9. Huellas en la pieza 03257: a) detalle del reverso de la pieza, con huella del punzón para realizar la decoración en relieve (aum.: $129,6 x)$; b) detalle del anverso con estriado central producido por el repujado y lineas de contorno dobles (aum.: 207,3x).

\subsection{La técnica decorativa}

Se identifica con la denominada de repoussé o repujado. Un sistema que ha sido observado en otros discos hallados en Europa, y que consiste en marcar el relieve desde el reverso, con una única línea o incisión, sobre una superficie de amortiguación (Fig. 9a). Desde el anverso se repasa mediante un punzón el contorno del relieve con el fin de resaltarlo (Comendador, 1999: 30; Armbruster, 2000: 130-131; Armbruster, et al., 2004, fig. IV, 181-183), en un proceso manual y reiterativo, muchas veces de forma imprecisa, generando lo que denominaremos 'salidas de línea' o 'dobles líneas' (Fig. 9b) y que requería de una sujeción sobre una superficie semirrígida para poder ejercer la presión del motivo que se plasmaba ${ }^{8}$.

8 En la actualidad se viene utilizando un soporte móvil de mediano tamańo y base cóncava que puede ser de

\subsection{Los motivos decorativos}

Como se ha señalado, los de los discos asturianos encuentran paralelos formales en el ámbito atlántico, repitiendo un patrón común, basado en un motivo central en forma de cruz, rodeado de círculos concéntricos, singularizándose algunos de ellos con incisiones o punteados regulares.

Mediante el análisis de huellas en la observación microscópica de las piezas se pueden identificar

distinto material, pero que ofrece una cara plana recubierta con una capa de pez -a partir de resinas- que mediante calentamiento se transforma en una superficie maleable y adherente que sujeta fácilmente objetos de pequeño tamaño como los que nos ocupan. Otras hipótesis apuntan la idea de que pudo utilizarse también una mezcla de cera y arcillas plásticas para conseguir una superficie de características y finalidad similar a la descrita, con la posibilidad de conseguir una superficie más o menos dura según requiera el trabajo. 

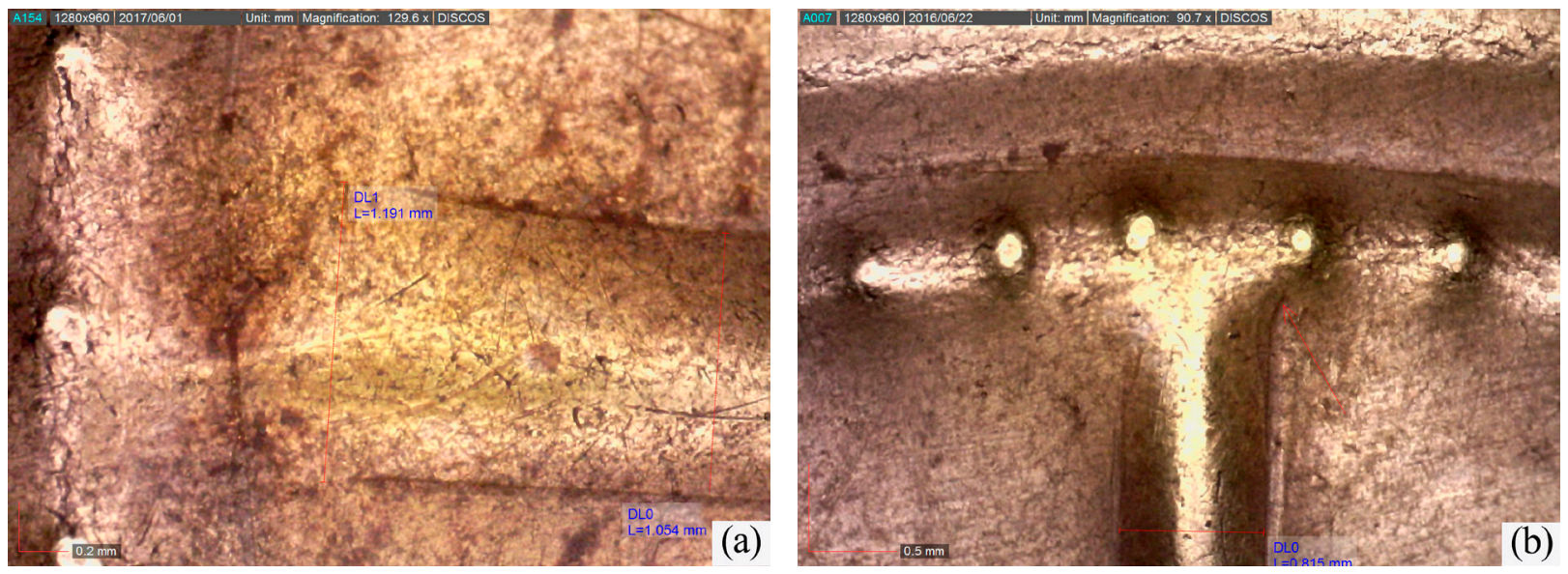

Fig. 10. Mediciones del grosor de los brazos de la cruz y ensanche producido durante el proceso de realización de los círculos exteriores: a) disco 03257 (aum.: 129,6x); b) disco 03258 (aum.: 90,7x).

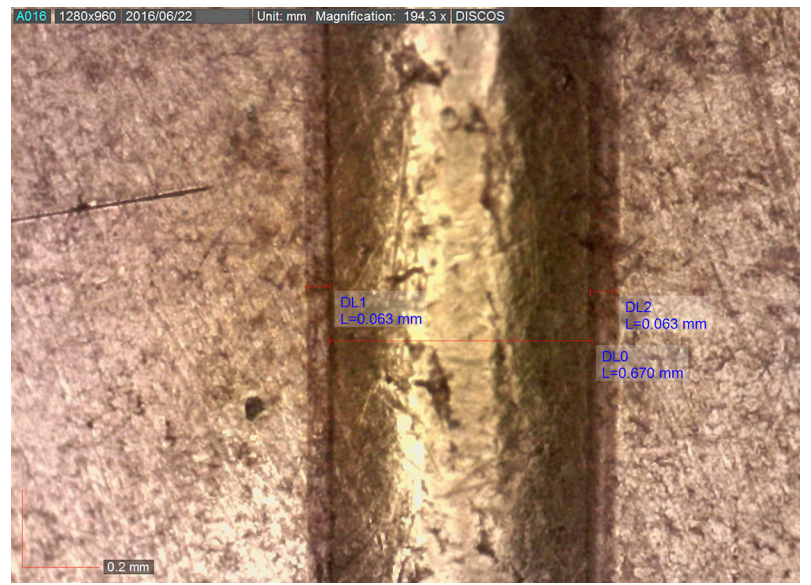

FIG. 11. Mediciones bajo binocular de las huellas del punzón en el anverso de la figura 03258 (aum.: 194,3x). aspectos relativos tanto a la técnica de elaboración de los motivos decorativos como al desarrollo de la secuencia operativa de trabajo. En una primera aproximación y a través de las mediciones realizadas sobre las distintas partes de los motivos, se evidencia un diseño ligeramente irregular, por su fabricación artesanal, pero muy cuidado. Pese a que ambos botones presentan una decoración similar, muestran ligeras diferencias, tal como ya se advirtiera sobre el tamaño.

En primer lugar se ejecutó el motivo cruciforme que marcará toda la decoración elaborada posteriormente. Se observan dos aspas, con un ancho aproximado de entre $0,80 \mathrm{~mm}$ y $1,19 \mathrm{~mm}$, que se ensanchan en el cruce con los círculos exteriores, por
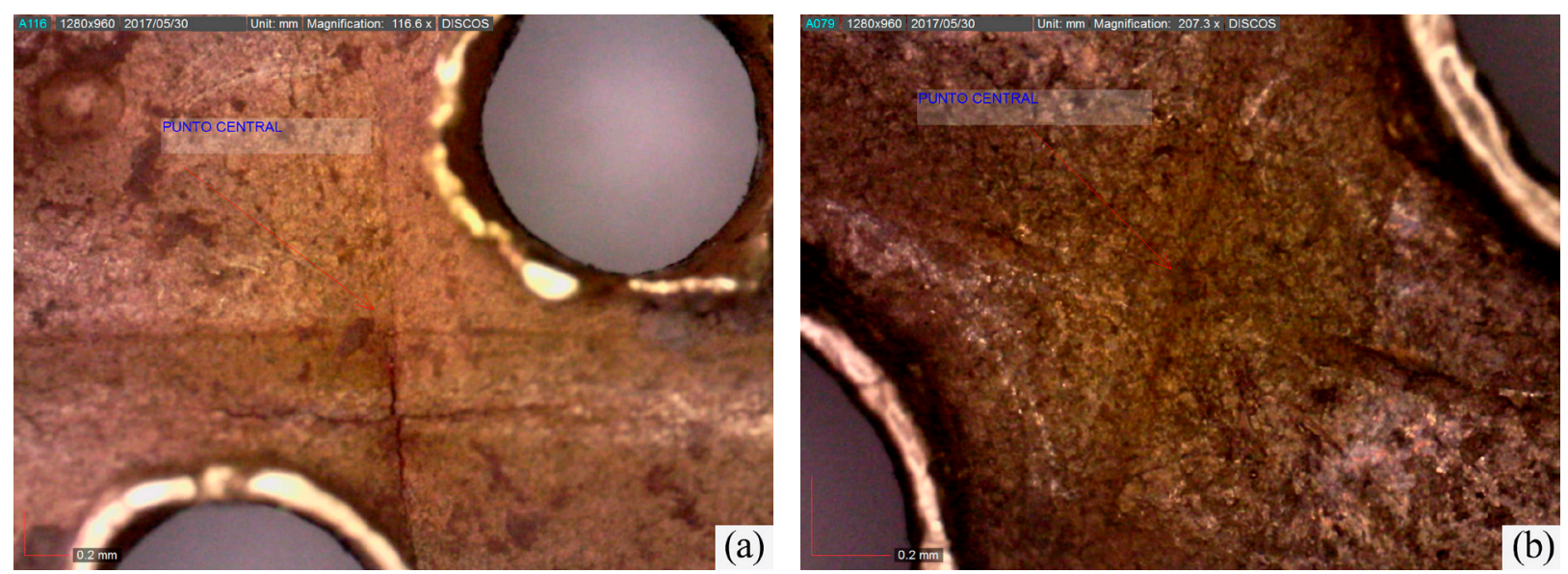

Fig. 12. Punto central del cruciforme visto desde el reverso: a) 03258 (aum.: 116,6x); b) 03257 (aum.: 207,3x). 


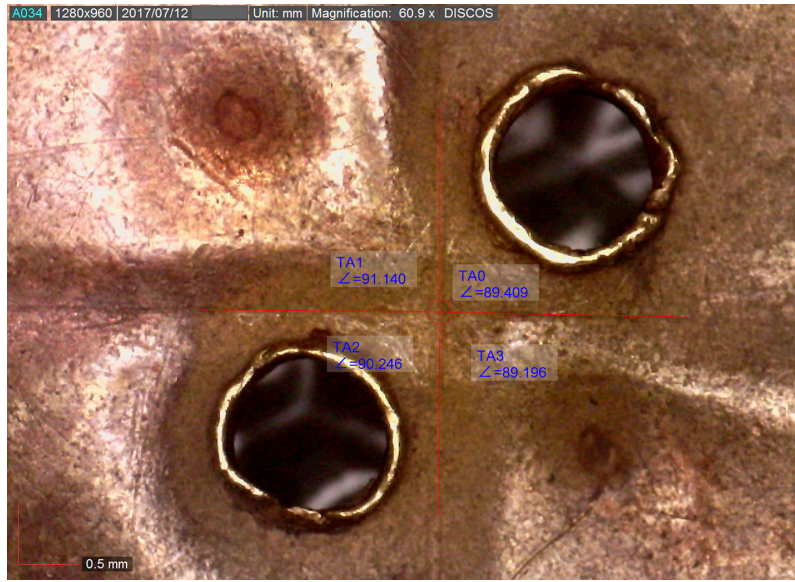

Fig. 13. Medición de los ángulos formados por el diseño del cruciforme desde el reverso de la pieza 03257 (medición bajo binocular; aum.: 60,9x).

lo que parece claro que primero se realizó el cruciforme y posteriormente los círculos (Fig. 10), deformando el relieve de las aspas de la cruz. Los brazos de la cruz se encuentran delimitados por dos líneas muy finas de sección en ' $U$ ' y espesor variable en torno a 0,04-0,07 $\mathrm{mm}$, en función de su intensidad y presión (Fig. 11). El motivo, tal como se explicaba anteriormente para la técnica de repujado, ha sido esbozado primeramente desde el reverso, marcando

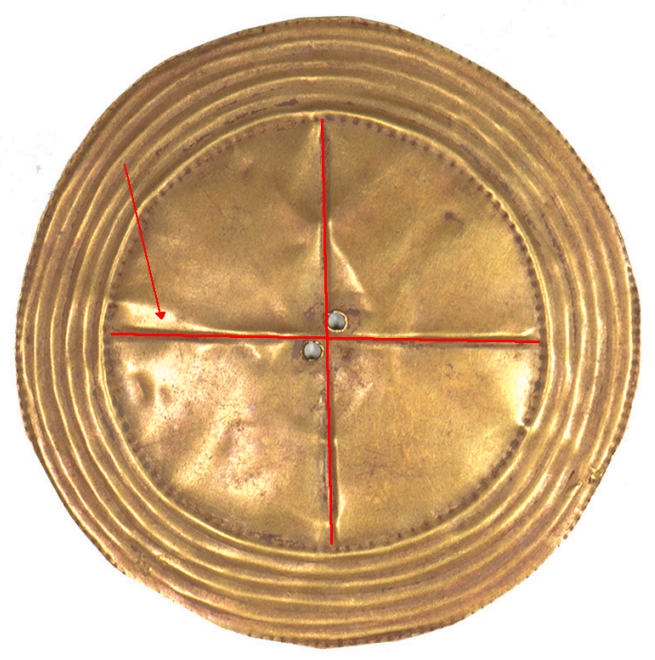

03258 | con una única línea o incisión, sobre una superficie de amortiguación, para posteriormente desde el anverso repasar su contorno, resaltando el relieve. Su longitud es de 20-21 mm, con ligeras diferencias en ambos discos. Desde el reverso se observa el punto central del trazado del cruciforme dibujando un ángulo que varía en ambos discos entre $87^{\circ}$ y $92^{\circ}$ aproximadamente (Fig. 12). Teniendo en cuenta que los discos sufren una pequeña deformación, el margen de error medido en el cruciforme sobre un ángulo recto perfecto $-90^{\circ}$ - resulta despreciable (Fig. 13). Este hecho plantea valorar la posibilidad del uso, para el diseño de la cruz, de una plantilla que trasladara el dibujo al reverso de la pieza, lo que explicaría que el motivo se observe en el reverso del disco con un trazo fino y continuo, sin apenas errores, ni líneas dobles y con una ligera inclinación en uno de los brazos que se repite en ambos discos (Fig. 14).

Enmarcando al cruciforme se dibujan una serie de círculos concéntricos. El primero y el último aparecen decorados mediante puntos repujados. La factura de los círculos concéntricos es más irregular obteniendo grosores muy variables, causados por un manejo precario del útil de trabajo. Se aprecian imperfecciones en el trazo e incluso líneas dobles

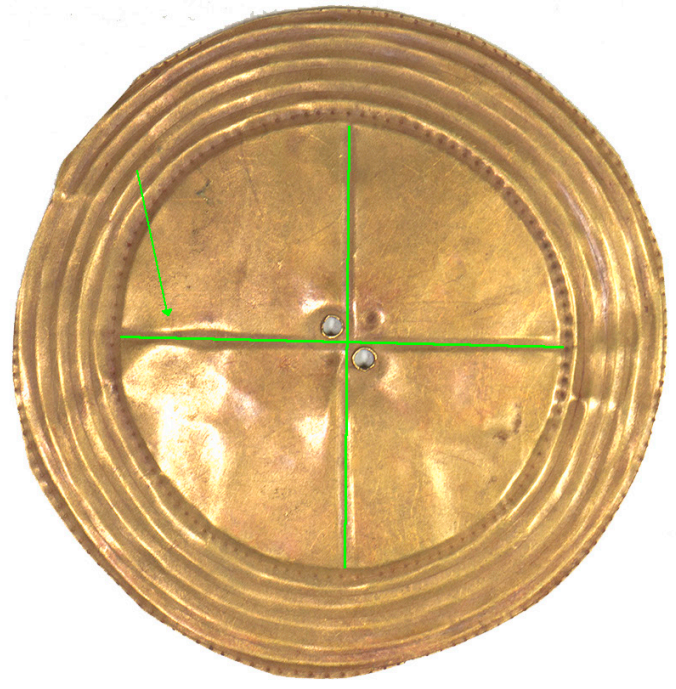

03257

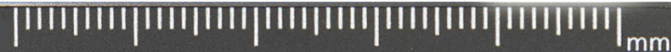

FIG. 14. Vista desde el reverso y esquema del motivo cruciforme, señalando una ligera inclinación del brazo correspondiente al cuadrante izquierdo de los discos 03258 y 03257. 

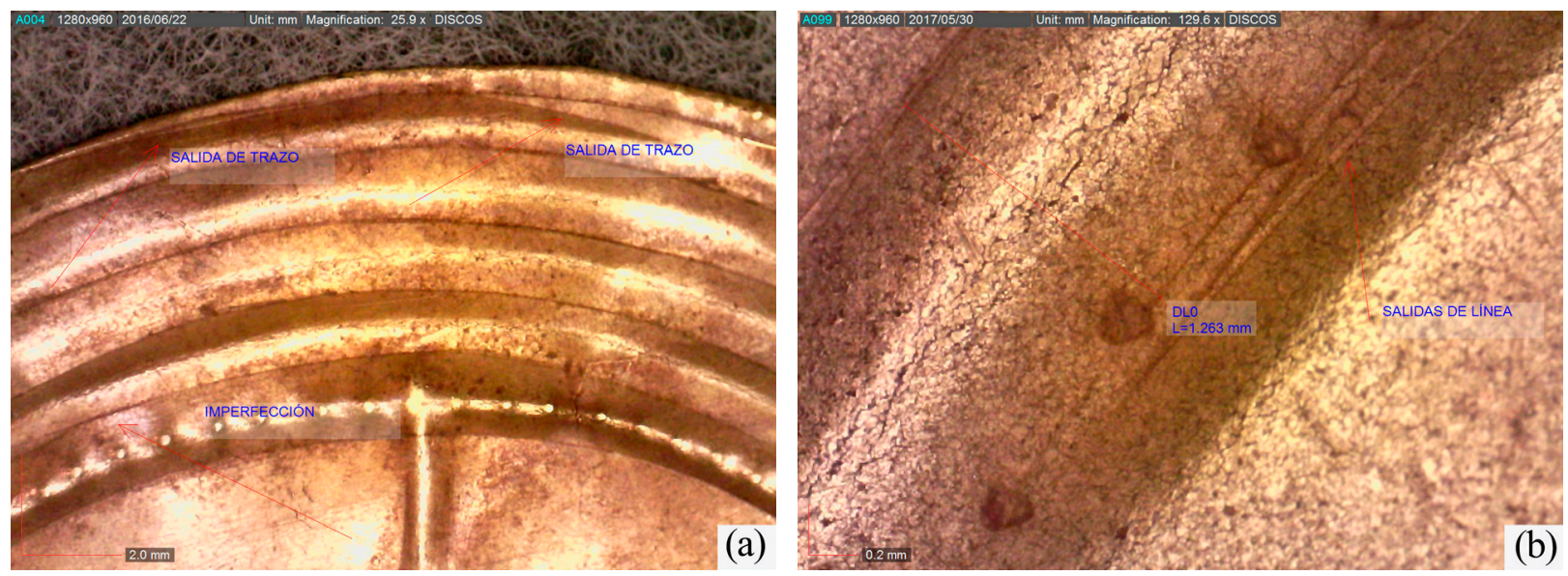

Fig. 15. Imágenes de la factura irregular de los círculos concéntricos: a) grosores irregulares de los círculos e imperfecciones (aum.: 25,9x); b) detalle de las líneas dobles efectuadas en uno de los círculos exteriores, visto desde el reverso de la pieza (aum.: 129,6x).

tanto en el anverso como en el reverso de las piezas (Fig. 15).

Como se apuntaba anteriormente, pese a seguir un esquema similar en ambos discos, se aprecian pequeñas diferencias de manufactura. Por ejemplo, en el botón 03257, el círculo punteado interior está flanqueado por dos líneas paralelas laterales que bordean su relieve, mientras que en el botón 03258, el anillo interno punteado carece de una de las líneas de contorno (Fig. 16). Este detalle hace que aquella pieza disponga un anillo de más, modificando el diseño original de seis a siete círculos concéntricos (Fig. 17).

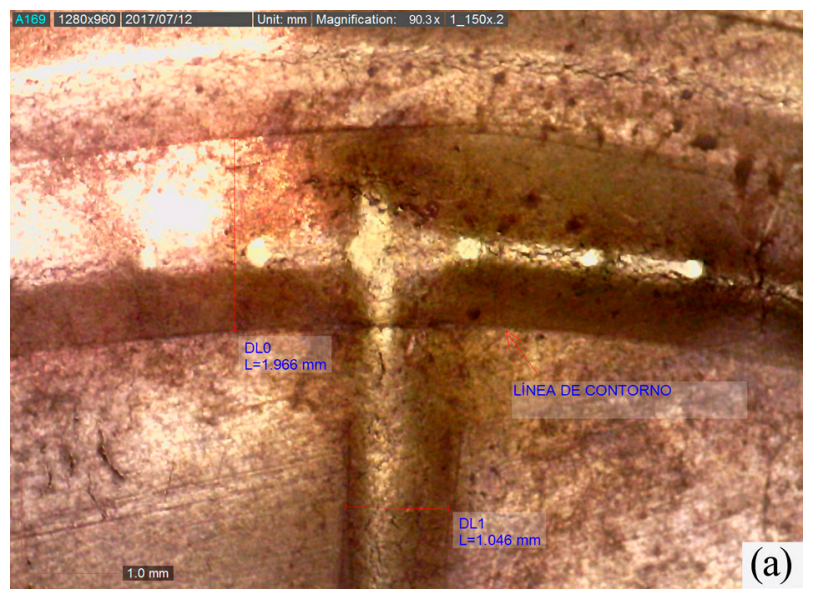

El relieve del punteado se realiza desde el reverso de la pieza siguiendo la línea central del diseño de los círculos (Fig. 18). A través de la medición mediante microscopía es posible comprobar irregularidades en las distancias entre cada uno de los puntos, que evidencian el uso de un único punzón simple para su manufactura.

El estudio minucioso de la ejecución de los círculos denota confusiones, salidas de trazo en la delimitación de los mismos, imperfecciones o errores propios de la confluencia del comienzo y final de las líneas, y gran variabilidad en los grosores, pudiendo concluir que su trazado no es homogéneo, ni en la

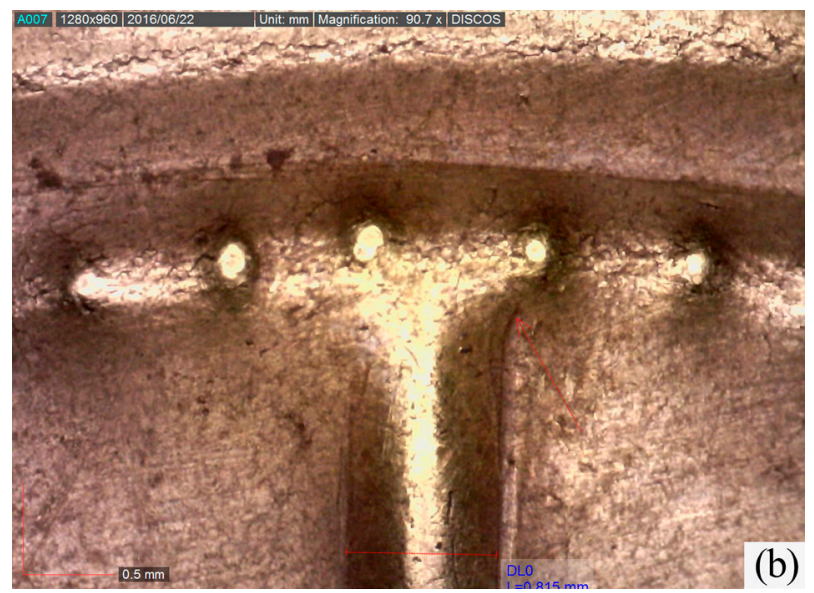

FIG. 16. Imagen de uno de los círculos punteados en cada uno de los discos: a) en 03257 se aprecian sendas líneas de punzón desde el anverso (aum.: 90,3x); b) en 03258 desaparece la linea inferior (aum.: 90,7x). 

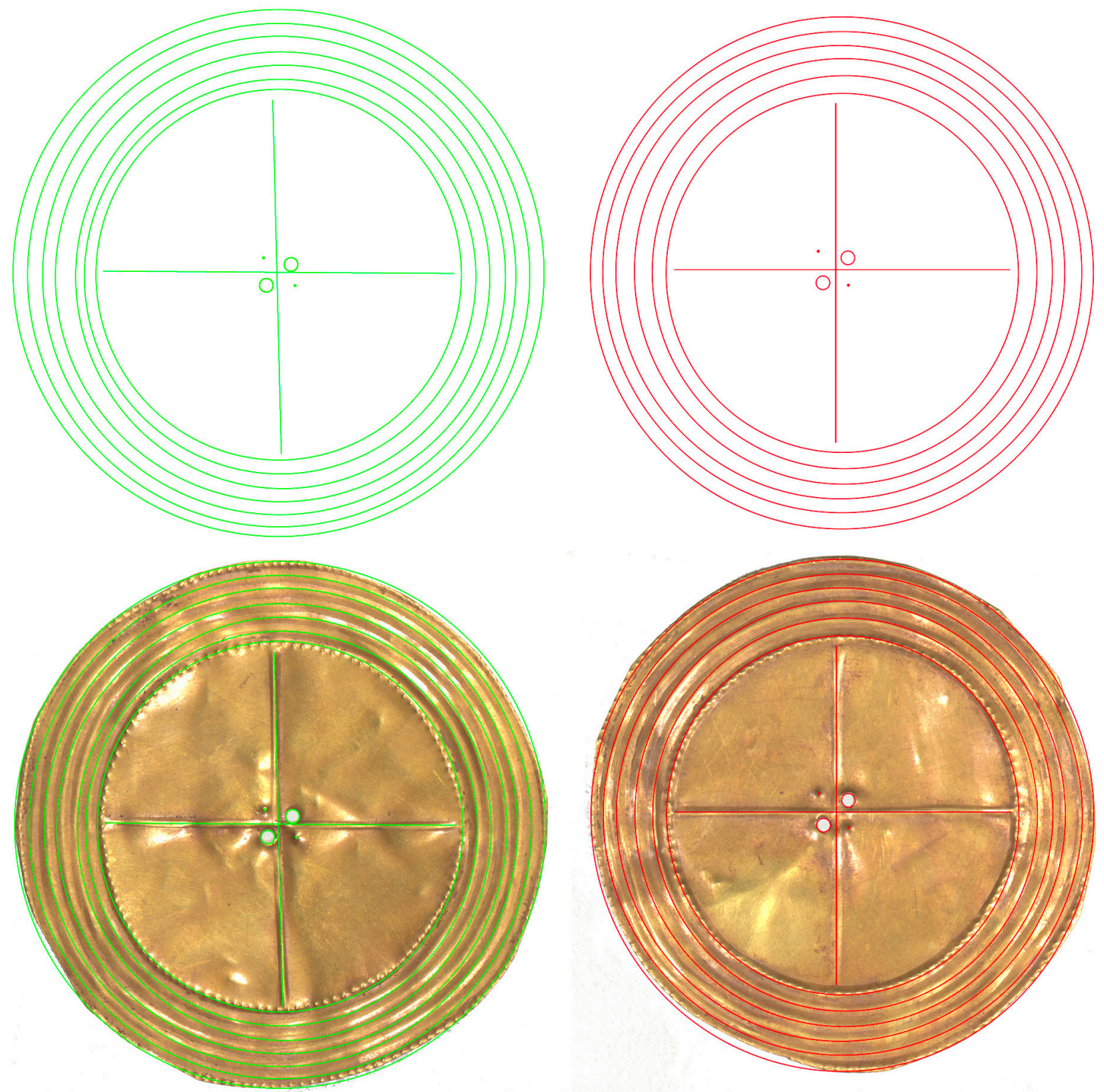

(a)

(b)

|

FIG. 17. Esquema gráfico del motivo decorativo: a) en el disco 03258; b) en el disco 03257.

propia pieza ni en comparación con su gemelo (Fig. 19), lo que demostraría, en este caso, la realización de los motivos mediante una aplicación manual y la ausencia, en este caso, de la ayuda de patrones o estampados para el trazado.

Una de las características de las piezas es la existencia de orificios centrales. En los discos asturianos se aprecian dos contrapuestos en dos de los cuadrantes. También contrapuestos, en clara simetría, se identifican dos repuntes o marcas realizadas desde el reverso, por lo que hay que entender que primero se marcaron los espacios de cada cuadrante en los que hacer el agujero y posteriormente se perforaron solo dos, contrapuestos, desde el anverso, tal como evidencian las huellas dejadas sobre la chapa de oro, probablemente para ocultar la rebaba. 


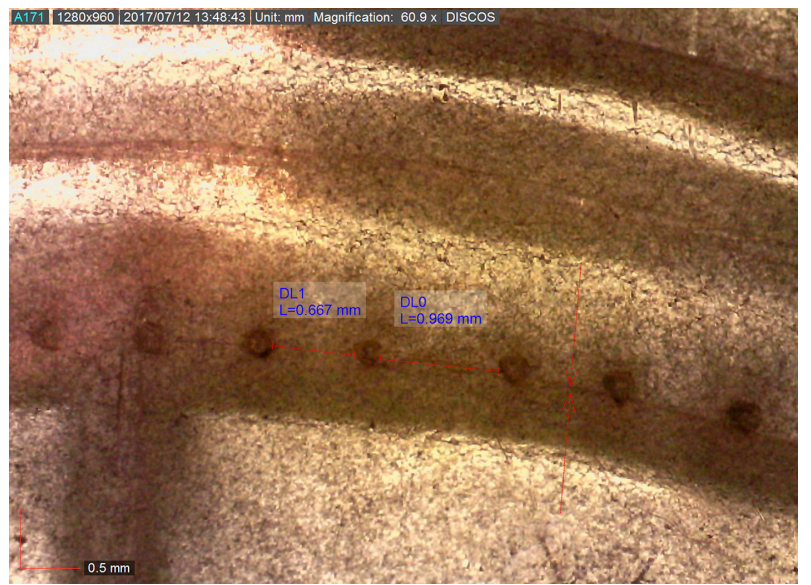

Fig. 18. Medición bajo binocular de la distancia entre dos de los puntos del círculo interior. La línea dibujada desde el reverso sirve de guía para el punteado (aum.: 60,9x).
En los dos orificios centrales el radio es prácticamente el mismo en ambos botones, en torno a 0,63 $\mathrm{mm}$, y la distancia entre los orificios y los puntos marcados varía mínimamente de un botón a otro (Fig. 20). La precisión en la distancia y su simetría lleva a pensar en la utilización de algún tipo de patrón para el marcado inicial, tal como también se planteaba para el dibujo del cruciforme.

Para la factura de los orificios, de forma general, se perforó la chapa desde el anverso, tal como atestiguan los rebordes que se aprecian en la parte posterior de las piezas. Sin embargo, en el disco n. ${ }^{\circ}$ 03257 también son visibles, en el anverso, pequeńos rebordes ligeramente desgastados o pulidos, lo que podría indicar que el artesano repasó alguno de los orificios posteriormente para terminar la labor
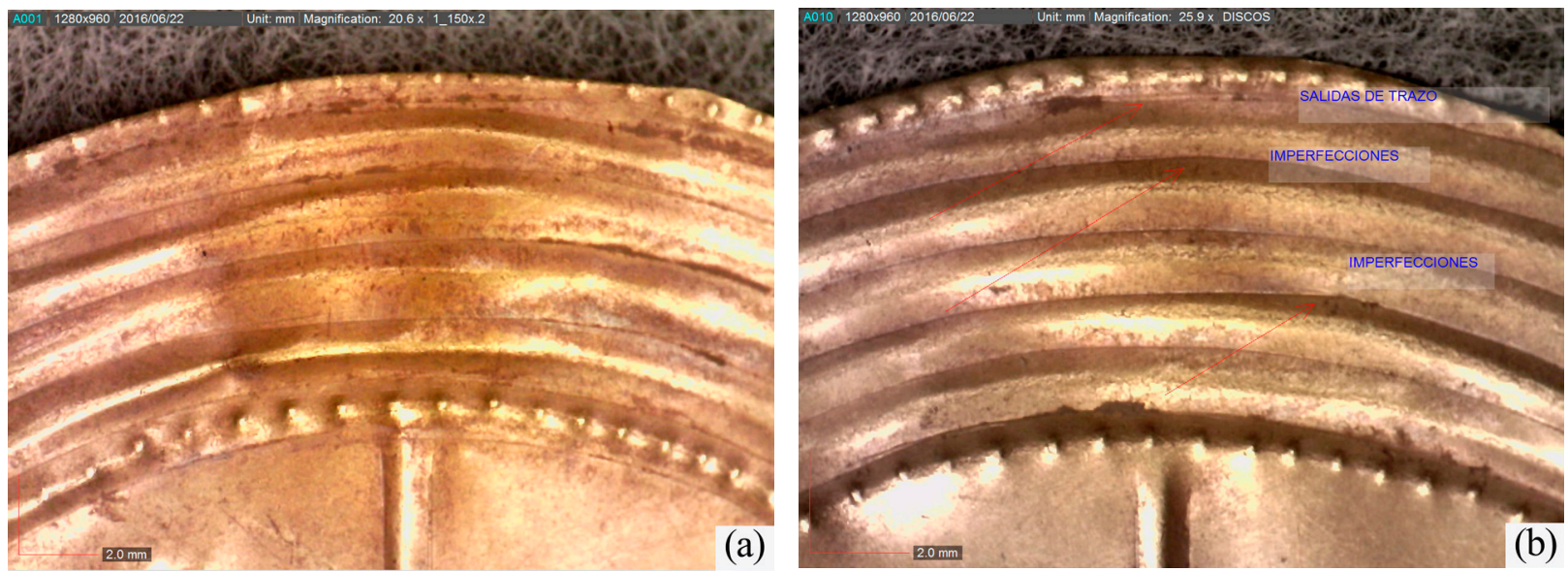

Fig. 19. Muestra de la diferente factura de los circulos concéntricos en ambos discos: a) 03257 (aum.: 20,6x); b) 03258 (aum.: $25,9 x$ ).
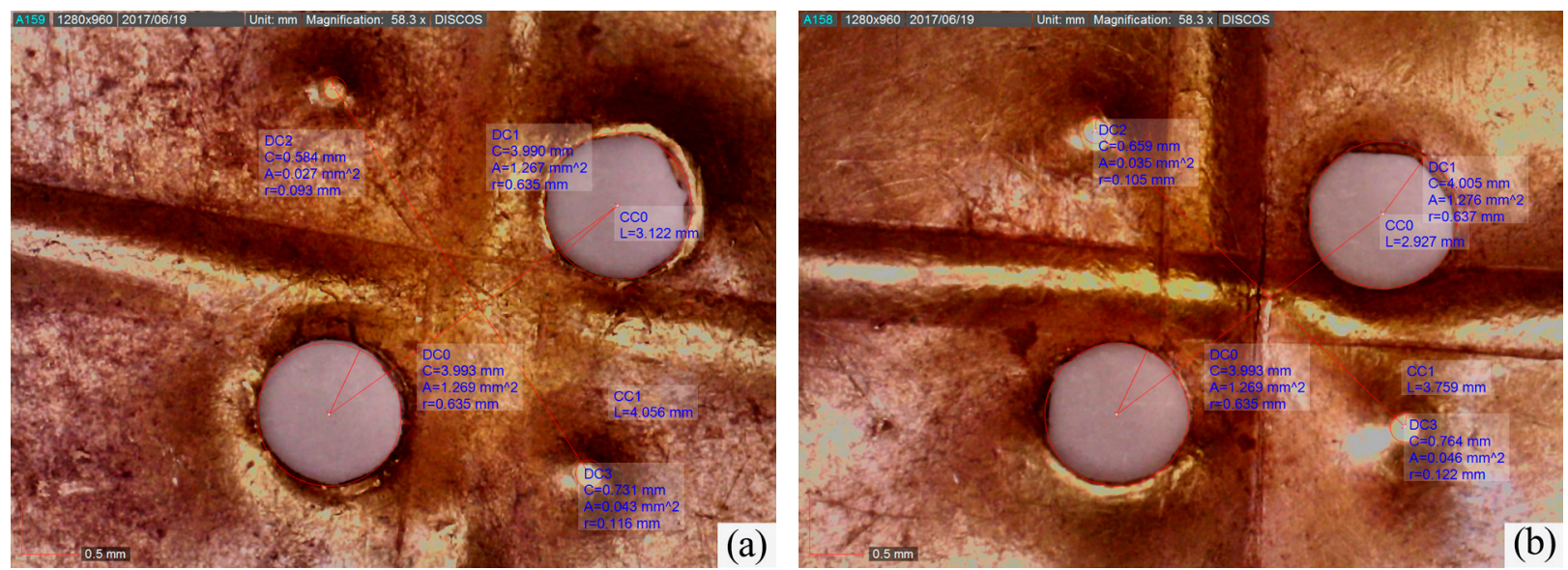

Fig. 20. Medidas y distancias tomadas entre los orificios y marcas de punzón: a) 03257 (aum.: 58,3x); b) 03258 (aum.: 58,3x). 
(Fig. 21). Sorprende en uno de los orificios del disco n. ${ }^{\circ} 03258$ lo que parecen ser restos de corte en su interior (Fig. 22). En este sentido y puesto que el tamaño de estas pequeñas perforaciones apenas difiere unas centésimas de milímetro en ambos discos, podríamos decir que el útil de trabajo tendría una superficie ligeramente cortante que generó agujeros del mismo tamańo y forma. Apoya esta idea el hecho de que no se aprecien fisuras ni grietas en su contorno, como cabría esperar si se hubiesen llevado a cabo mediante el sistema de presión y rotura, con la ayuda de un punzón apuntado.

A juzgar por el estado de los orificios, sin imperfecciones, rozaduras ni fisuras, ni la existencia -ya seńalada- de rayones, estrías en el reverso o desgastes

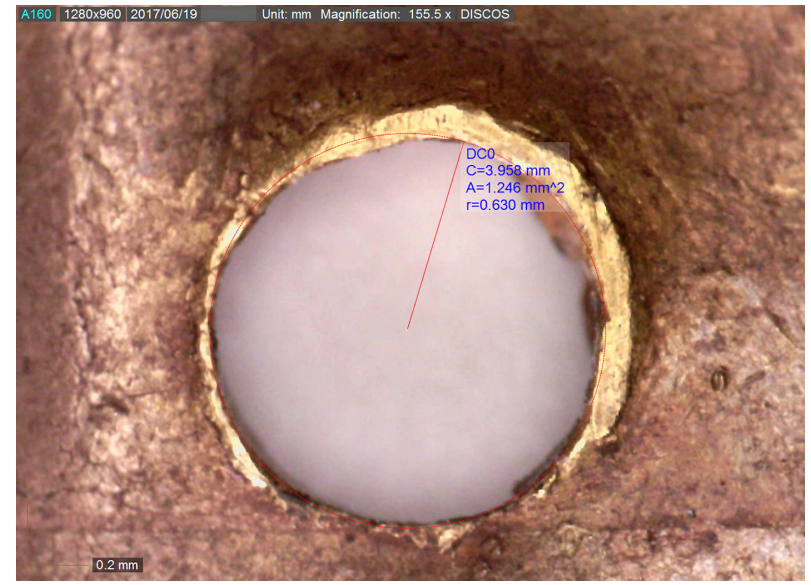

FIG. 21. Restos de rebabas con huellas de pulido en el anverso de la pieza del disco 03257 (aum.: 155,5x).

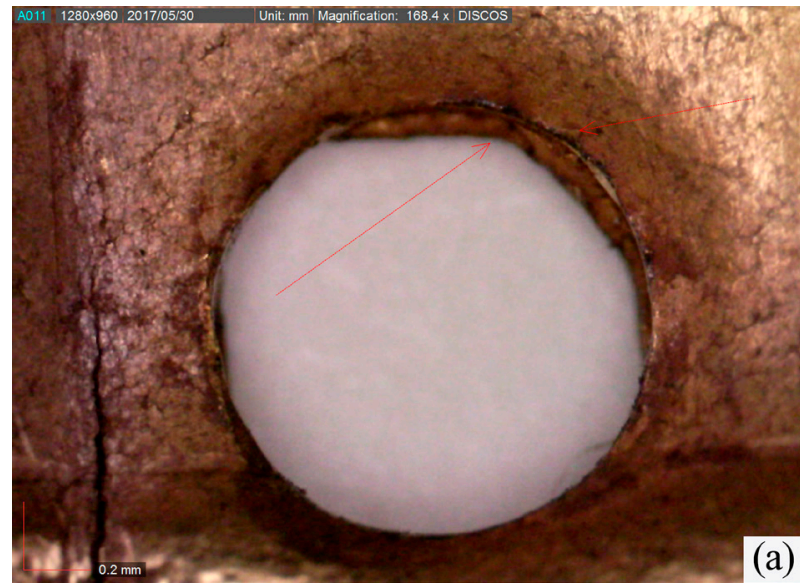

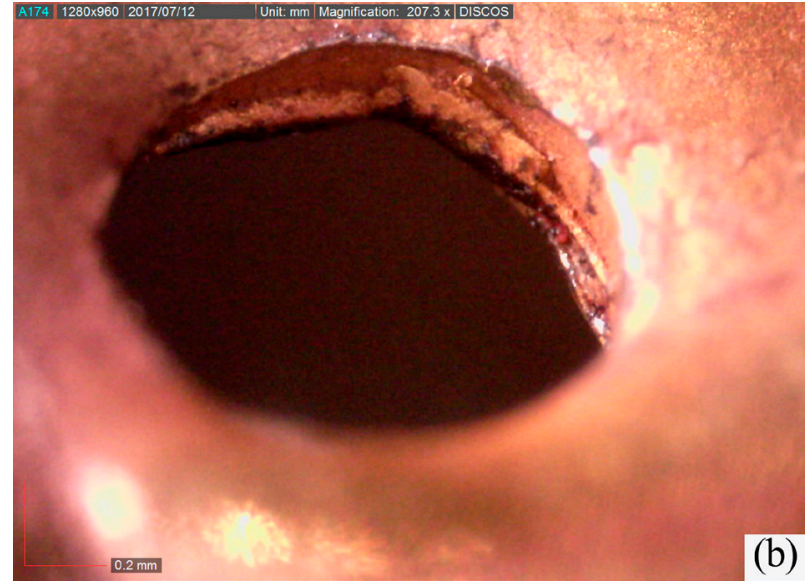

Fig. 22. Huellas de corte en uno de los orificios del disco 03258: a) vista frontal desde el anverso (aum.: 168,4x); b) vista oblicua desde el anverso (aum.: 207,3x).

(Fig. 23), se puede afirmar que los botones no tuvieron un uso ni intenso ni prolongado, y presuponer que dicho uso fue estrictamente simbólico, posiblemente funerario, por el contexto en el que suelen aparecer estas piezas.

\subsection{Recorte de sobrantes}

El recorte final de los discos se realiza con posterioridad a la decoración. En este caso se advierte en el proceso un gesto impreciso, eliminando parte de los anillos concéntricos del perímetro de la pieza (Fig. 24). Así, en el botón 03257 se elimina un tercio del anillo exterior y en el 03258 se elimina parte de la línea de puntos. No puede concretarse con precisión el útil empleado para esta acción, ya que se observan tanto rebabas en algunas zonas del borde (Fig. 25a) como huellas perpendiculares y paralelas a la dirección de la hoja de metal (Fig. 25b), que podrían atribuirse a un limado posterior.

En suma, el proceso descrito es coincidente, en lo que conocemos, con las técnicas de producción y decoración de los discos procedentes de las Islas Británicas, con un diseño en el que se combinan los motivos angulares y circulares que requiere, para su ajuste en un espacio circular, una planificación y esbozo previo (Cahill, 2016: 26). 


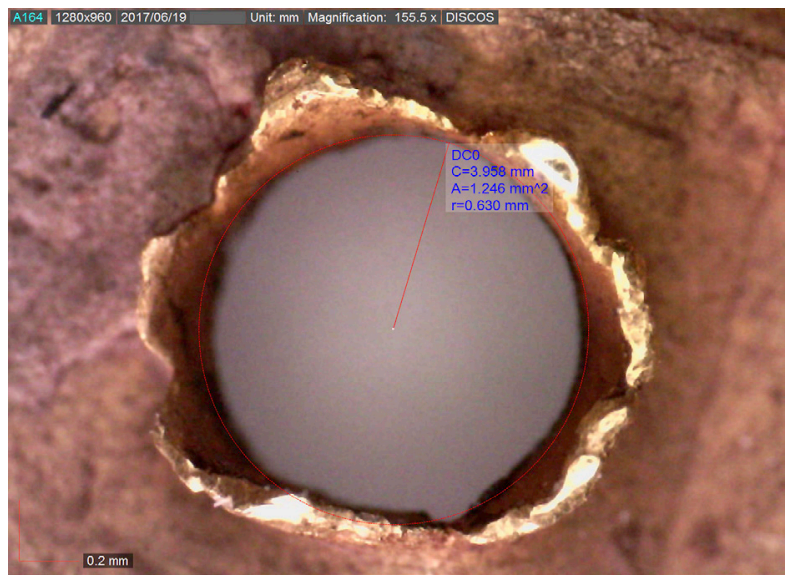

FIG. 23. Imagen de las rebabas en el reverso de los orificios de la pieza 03258 (aum.: 155,5x).

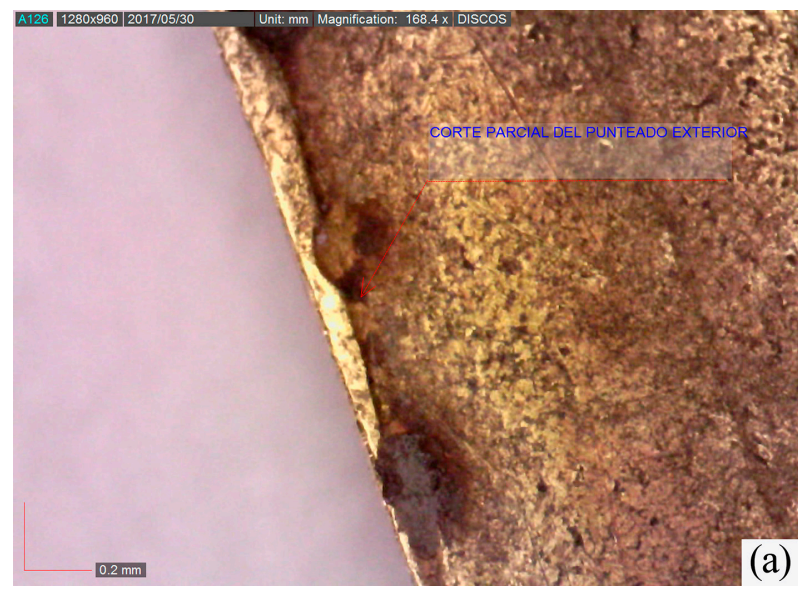

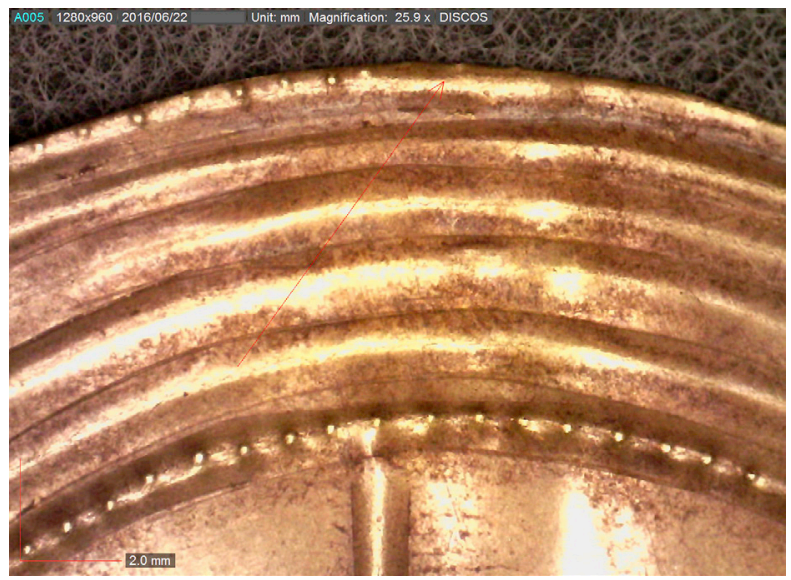

FIG. 24. Recorte imperfecto del último círculo concéntrico, asi como de la linea de puntos en la pieza 03257 (aum.: 25,9x).

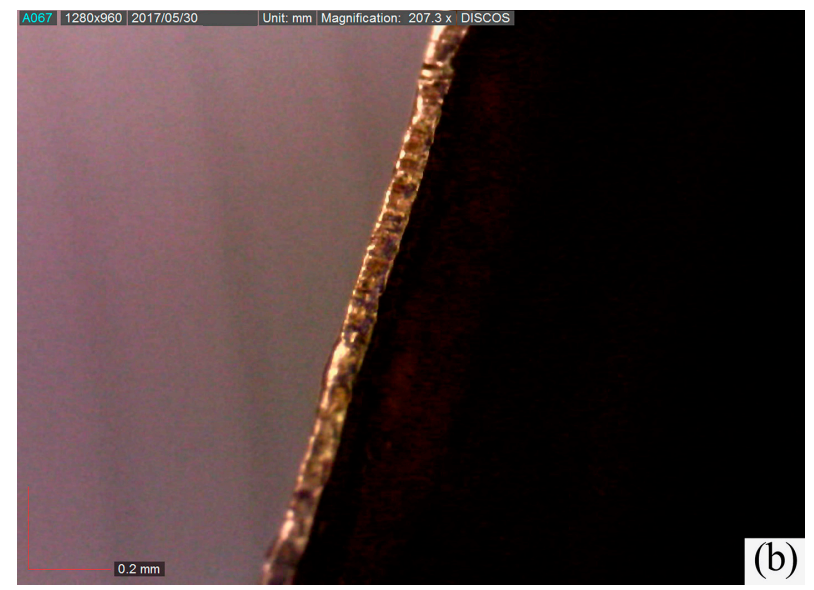

FIG. 25. Huellas producidas por el trabajo de recorte final de la pieza: a) rebabas en el perimetro del disco al seccionar la lámina de oro (aum.: 168,4x); b) fotografía macro de la huella en el borde de la lámina en sentido perpendicular al corte (aum.: 207,3x).

En este tipo de piezas no hay evidencias de la utilización de troqueles para definir la decoración. Aun cuando recientemente se ha identificado un objeto que pudo tener esa finalidad, las láminas decoradas a las que se pudo estampillar la decoración resultan mucho más finas y endebles, como sería el caso del disco Sparrograda (Cahill, 2016: 28-29). En este sentido, en los discos asturianos se pudieran haber utilizado, tal como se ha señalado, algunos patrones o matrices para el dibujo inicial o marcado de alguna de las figuras ${ }^{9}$; sin embargo, el diseño final se ejecuta

9 Al respecto, es sugerente la observación, destacada por distintos autores (Garrido, 2000: 195-196), sobre la a mano, sin otro tipo de ayuda. Una característica que se evidencia por el uso de líneas de ejecución o dibujo previo de los motivos, por las 'salidas de línea' o 'dobles líneas' en los trazos, las irregularidades en el dibujo de los círculos concéntricos, así como por el hecho de que entre ambos botones existen ligeras diferencias que estarían ausentes de haber utilizado un troquel o sello en su ejecución.

Un hecho repetitivo es la asociación de estos discos en pares que, siendo a simple vista idénticos,

utilización de técnicas impresas para lo que se ha considerado motivos incisos en algunas cerámicas. Algo que pudiera repetirse en este caso. 
evidencian diferencias propias de los trabajos artesanales, especialmente en el tamaño de las piezas. Esta faceta podría deberse a que fueron recortadas a mano y, por tanto, justificarse por la pericia del orfebre, máxime cuando en los asturianos parece evidente que la decoración fue completada de forma idéntica y fue el recorte final al que se debe la diferencia de 3,5 mm de diámetro y la desaparición parcial del circulo repujado con puntos. Si esta acción fue casual o deliberada para conseguir una réplica de la observación astral, como se ha propuesto (Cahill, 2016: lám. 5), es algo que no podemos contrastar.

Respecto a la secuencia operativa de trabajo en el diseño, creemos, en base a los indicios observados, que primero se realiza el motivo central en forma de cruz, el cual marcará toda la decoración elaborada con posterioridad, ya que el punto central del cruciforme es a su vez el centro de los círculos exteriores. Por otra parte, las aspas o brazos se ensanchan en el punto de encuentro con los círculos (Fig. 11), confirmando que los círculos fueron realizados $a$ posteriori y a mano, tomando como centro el cruciforme. Tan solo en una de las piezas -03257- es posible apreciar un esbozo del punto central de la cruz, marcado desde el anverso de la misma. Este punto pudo haber servido, a partir de las apreciaciones anteriores, como guía para el desarrollo del resto de los motivos decorativos. (Fig. 26). Posteriormente, se llevan a cabo los orificios centrales y sus correspondientes punteados contrapuestos, que se sitúan, en parte, sobre los brazos del cruciforme (Fig. 20). Este dato nos indica que su realización es posterior a la factura del resto de la decoración. Por último, se procede al recorte definitivo del disco según el contorno de los círculos concéntricos.

\section{Conclusiones}

Los análisis elementales micrométricos han permitido identificar, por vez primera, la composición de estas piezas de los inicios de la Edad de los Metales, atribuidas a la región asturiana. La composición elemental apunta al uso de un oro aluvial como

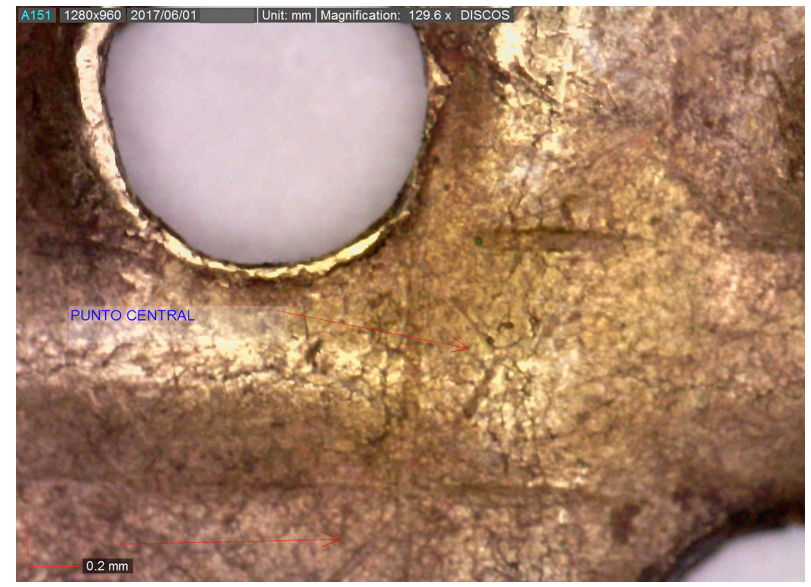

FIG. 26. Líneas realizadas con punzón desde el anverso del disco para determinar el punto central del diseño (aum.: 129,6x).

materia prima, y los elementos traza identificados -sobre todo la presencia de pequeñas cantidades de estaño- sugieren una procedencia no local. Aunque podría ser próxima - de áreas más al o-, no es posible descartar, bien al contrario, un origen en el área meridional de las Islas Británicas donde se conoce la mayor concentración de hallazgos similares asociados al fenómeno campaniforme.

Sea de un origen u otro, su existencia viene a confirmar, bien por la procedencia del metal, bien por el diseño, las relaciones e intercambios desde los últimos siglos del III milenio a. C., entre territorios próximos del ámbito atlántico. La mayoría de estos hallazgos se asocian recurrentemente a lugares en los que se confirma la explotación de recursos primarios, lo que, inevitablemente, se asocia al surgimiento de élites o jefaturas. Así se repetiría con los discos asturianos, lo que ha sido argumentado para refutar la abrupta topografía como la causante de un efímero aislamiento de aquel territorio que a la luz de estas y otras referencias se va diluyendo.

Los procesos y técnicas de fabricación y decoración de las láminas han podido ser descritos, contrastados y documentados mediante el estudio detallado de las piezas. A partir de dichas observaciones se confirmaría que algunos elementos de la decoración de las piezas fueron plasmados con un patrón, si bien su ejecución se realizó probablemente 
de forma manual por un mismo taller/artesano a tenor de las similitudes de ambas piezas, que tienen diferencias propias de objetos manufacturados. Estudios similares permitirán identificar talleres o ejecutores y seguir la difusión e intercambio de estas piezas que debieron ser, como hoy nos lo parece, objetos suntuarios, utilizados con una finalidad representativa y/o ritual, con un seguro significado definido por la combinación de motivos cuya presencia, a tenor de la documentación de utilización de patrones, no resultaría aleatoria.

Los motivos decorativos apuntan a una clara tradición con lo campaniforme y recurrentemente en la Península Ibérica, con la modalidad incisa, al igual que la mayoría de los hallazgos señalan su indudable vinculación con inhumaciones asociadas al ritual protagonizado por los portadores de dicha cerámica, especialmente en el marco Atlántico en el que se localizan mayoritariamente. En el ámbito peninsular, el número de asociaciones evidencia que la orfebrería del oro en el centro y no adquiere un destacado protagonismo en dicho momento, si bien se advierte que dicha corriente no es única por la existencia en el área oriental de otros objetos que evocan una difusión de trazabilidad continental.

Finalmente, los discos planos perforados tienen una indudable asociación a inhumaciones y su aparición por pares es reiterada y repetitiva. Por los orificios centrales, para la fijación, se consideran botones, si bien algunas piezas con las perforaciones laterales pudieran indicar un uso como adornos o colgantes que adquirirían movimiento al compás del del portador, constituyendo un llamativo referente para quienes los observaran. Esto sería aceptable si el portador de estos objetos se moviera, lo que no debe darse por supuesto, ya que la mayoría de estas piezas aparecen asociadas a rituales de inhumación y carecen de huellas de uso.

\section{Bibliografía}

Álvarez, R. (2003): "Mineralogical and geochemical characterization of an epithermal gold deposit in northwestern Spain”, Memórias e Noticias, 2, Nova Série, pp. 195-204.
Arias, D.; Corretgé, L. G.; SuÁrez, O.; Villa, L.; Cuesta, A. y Fernández SuÁrez, J. (1993): "Gold and base metal vein mineralization and associated silicate bodies in the Ibias area (Asturias, Nw Spain)", Chronique de la Recherche Minière, 513, pp. 25-36.

Arias, D.; Corretgé, L. G.; Villa, L.; Gallastegui, G.; SuÁrez, O. y Cuesta, A. (1997): "A Sulphur isotopic study of the Navia gold belt (Spain)", Journal of Geochemical Exploration, 59, pp. 1-10.

Armbruster, B. (1999): "Techniques d'orfèvrerie préhistorique des tôles d'or en Europe Atlantique des origines à l'introduction du fer". En CAuvet, B. (ed.): L'Or dans l'Antiquité, de la mine à l'objet. Supplément Aquitain, 9. Bordeaux, pp. 237-249.

Armbruster, B. (2000): Goldschmiedekunst und Bronzetechnik Studien zum Metallhandwerk der Atlantischen Bronzezeit auf der Iberischen Halbinsel. Monographien Instrument, 15. Montagnac: Edit. Monique Mergoil.

Armbruster, B.; Bello, J. M.a; Comendador, B. y Perea, A. (2004): "Relaciones atlánticas en los inicios de la metalurgia. La gargantilla de tiras y el conjunto de las láminas áureas de Cícere (Santa Comba, A Coruña, España)". En Perea, A.; Montero, I. y García Vuelta, O. (eds.): Cronología del oro Antiguo: Europa y América. Anejos de Archivo Español de Arqueología, xxxiI. Madrid: csic, pp. 173-188.

Armbruster, B. y Comendador, B. (2015): "Early gold technology as an indicator of circulation proceses in Atlantic Europe". En Prieto, P. y Salanova, L. (ed.): The Bell Beaker transition in Europe. Mobility and local evolution during the $3^{\text {rd }}$ millennium $B C$. Oxford: Oxbow Books, pp. 140-149.

Armbruster, B. y Parreira, R. (1993): Colecção de ourivesaria I. Do Calcolítico à Idade do Bronze. Lisboa: Instituto Português de Museus.

Bandera; M. a L.; Ortega, I.; Gómez, B.; Ontalba, M. ${ }^{a}$ A. y Respaldiza, M. A. (2010): "Caracterización del taller de orfebrería de Gadir mediante técnicas de análisis nucleares", Mainake, xxxII, pp. 37-59.

Blasco, C. y Ríos, P. (2010): "La función del metal entre los grupos campaniformes. Oro versus cobre. El ejemplo de la Región de Madrid", Trabajos de Prehistoria, 67 (2), pp. 359-372.

Cahill, M. (2015): "Here comes the sun... Mary Cahill explores on solar symbolism in Early Bronze Age Ireland", Archaeology Ireland Spring, pp. 26-33.

Cahill, M. (2016): "A stone to die for Early Gold working in Waterford", Archaeology Ireland Autumn, 26, pp. 26-29. 
Campillo, J. (2004): “Dos sortijas cubrededos de oro halladas en túmulo campaniforme de Tablada de Rudrón (Burgos)", Kobie, 6 (1), pp. 257-268.

Chapman, R.; Leake, R. y Styles, M. (2002): "Microchemical characterization of gold grains as an exploration tool", Gold Bulletin, 35 (2), pp. 53-65.

Comendador, B. (1995): "Caracterización de la metalurgia inicial gallega: una revisión”, Trabajos de Prehistoria, 52, 2, pp. 111-129.

Comendador, B. (1997): Los inicios de la Metalurgia en el noroeste de la Península Ibérica. Colección Tesis Doctorales [CD-Rom]. Santiago de Compostela: USC. Comendador, B. (1999): "Noroeste". En Delibes, G. y Montero, I. (coords.): Las primeras etapas metalúrgicas en la Peninsula Ibérica. II. Estudios Regionales. Madrid: Instit. Univ. Ortega y Gasset-MEC, pp. 10-39.

Comendador, B.; Millos, J. y Álvarez-Iglesias, P. (2014): "Provenance of the prehistoric silver set of Antas de Ulla, north-western Iberia, using lead stable isotope ratios". En Meller, H.; Risch, R. y PernicKA, E. (eds.): Metals of power early gold and silver. $\sigma^{\text {th }}$ Archaeological Conference of Central Germany. Halle: Tagungen des Landesmusseums für Vorgeschichte, 11/I, pp. 285-308.

Correia, V. H. (2013): “A ourivesaria arcaica no ocidente peninsular. Estado da questão, problemáticas arqueológicas e perspetivas de desenvolvimento do campo de estudo", O Arqueólogo Português, s. v, 3, pp. 15-80.

De Blas, M. A. (1983): La Prehistoria Reciente en Asturias. Estudios de Arqueología Asturiana, 1. Oviedo: Fund. Pública Cuevas y Yacimientos Prehistóricos de Asturias-Principado de Asturias.

De Blas, M. A. (1990): "Excavaciones arqueológicas en la necrópolis megalítica de La Cobertoria (divisoria Lena-Quirós) y en los campos de túmulos de Piedrafita y El Llanu La Vara (Las Regueras)”. En Excavaciones arqueológicas en Asturias, 1983-86. Oviedo, pp. 69-77.

De Blas, M. A. (1999): “Asturias y Cantabria”. En Delibes, G. y Montero, I. (coords.): Las primeras etapas metalúrgicas en la Península Ibérica. II. Estudios Regionales. Madrid: Inst. Univ. Ortega y Gasset-MEC, pp. 41-62.

De Blas, M. A. (2011): "De la caverna al lugar fortificado: una mirada de la Edad del Bronce en el territorio astur-cantábrico", Quaderns Prehistoria Castellonense, 29, pp. 105-134.

De Blas, M. A. y López Álvarez, J. (2001): "Sobre la búsqueda tradicional de oro en yacimientos arqueológicos y noticia de un probable tesoro prehistórico en tierras de Grado en el s. Xvi", Ástura. Nuevos cartafueyos d'Asturies, 11, pp. 9-16.

De Blas, M. A. y Rodríguez del Cueto, F. (2015): "La cuestión campaniforme en el Cantábrico Central y las minas de cobre prehistóricas de la sierra del Aramo", Cuadernos Prehistoria y Arqueología de la UAM, 4, pp. 165-179.

Delibes, G. (1977): El Vaso Campaniforme en la Meseta Norte Española. Studia Archaeologica, 46. Valladolid.

Delibes, G. (1978): "Reinterpretación del ajuar campaniforme de Villar del Campo. Nuevos elementos de juicio para valoración de la incidencia europea en el mundo de Ciempozuelos", Celtiberia, 28, pp. 267-286.

Ehser, A.; Borg, G. y Pernicka, E. (2011): "Provenance of the gold of the Early Bronze Age Nebra Sky Disk, central Germany: geochemical characterization of natural gold from Cornwall", European Journal of Mineralogy, 23, pp. 895-910.

Escortell, M. (1982): Catálogo de las Edades de los Metales del Museo Arqueológico de Oviedo. Oviedo: Principado de Asturias.

Fernández Ochoa, C. (1995): Astures. Catálogo de la Exposición. Gran Enciclopedia Asturiana. Gijón.

Fitzpatrick, A. P. (ed.) (2013): The Amesbury Archer and the Boscombe Bowmen. Bell Beaker Burials on Boscombe Down, Amesbury, Wiltshire. Archaeology Report, 27. Wessex.

Fitzpatrick, A. P.; Delibes, G.; Guerra, E. y VelasCO, J. (2016): "Bell Beaker connections along the Atlantic façade: the gold ornaments from Tablada de Rudrón, Burgos, Spain”. En Guerra, E. y LieSAU, C. (eds.): Analysis of the Economic Foundations Supporting the Social Supremacy of the Beaker Groups. Proceedings XVII UISPP World Congress. Vol. 6/Session B36. Oxford: Archaeopress, pp. 37-54.

García-Rodríguez, G.; García-Iglesias, J. y Loredo, J. (1991): "Estudio de las mineralizaciones auríferas en la cuenca alta del río Suarón (zona occidental de Asturias)", Boletín de la Sociedad Española de Mineralogia, 14, pp. 171-181.

Garrido, R. (2000): El Campaniforme en la Meseta Central de la Península Ibérica (c. 2500-2000 AC). BAR Intern. Ser., 892. Oxford: Archaeopress.

Garrido, R.; Rojo, M. A. y García Martínez de Lagrán, I. (2005): "El Campaniforme en la Meseta central de la Península Ibérica”. En Rojo, M. A.; Garrido, R. y García Martínez de Lagrán, I. (coords.): El Campaniforme en la Peninsula Ibérica y su contexto europeo. Arte y Arqueología, 21. Valladolid, pp. 411-437. 
GiBson, C. (2013): "Beakers into Bronze: Tracing connections between western Iberia and the British Isles 2800-800 BC". En Koch, J. T. y Cunliffe, B. (eds.): Celtic from the West 2, Rethinking the Bronze Age and the Arrival of Indo-European in Atlantic Europe. Oxford: Oxbow Books, pp. 71-100.

Hartmann, A. (1982): Prähistorische Goldfunde aus Europa II. Spektralanalytische Untersuchungen und deren. Auswertun SAM, 5 Gbr. Mann. Berlin.

Hernando, A. (1983): "La Orfebrería durante el Calcolítico y Bronce Antiguo en la Península Ibérica", Trabajos de Prehistoria, 40, pp. 85-138.

Hernando, A. (1991): "Una Historia que comienza en el Calcolítico. Los primeros orfebres”. En Perea, A. (dir.): Orfebrería prerromana. Arqueología del Oro. Catálogo de la Exposición. CajaMadrid/Comunidad de Madrid, pp. 7-8.

Kaul, F. (2003): "Der Mythos von der Reise der Sonne. Darstellungen auf Bronzegegenstätnden der späten Nordischen Bronzezeit”. En Springer, T.: Gold und Kult der Bronzezeit. Nürnberg: Germanisches Nationalmuseum, pp. 36-51.

Kelly, E. P. y Cahill, M. (2010): "Safe secrets 1, an early Bronze Age detective story Country Roscommon", Archeology Ireland, 24 (2), pp. 5-6.

Kristiansen, K. y Larsson, T. B. (2006): La emergencia de la sociedad del Bronce. Viajes, transmisiones y transformaciones. Barcelona: Bellaterra.

Liesau, C. y Blasco, C. (2011-12): "Materias primas y objetos de prestigio en ajuares funerarios como testimonios de redes de intercambio en el Horizonte campaniforme", Cuadernos de Prehistoria y Arqueología de la UAM, 37-38, pp. 209-222.

Liesau, C.; Guerra, E.; Delibes, G.; Blasco, C. y Ríos. P. (2016): "Copper weapons, gold and ivory: long-distance exchanges, and emulation among the atlantic beaker groups", Musaica Archaeologica, 1 (1), pp. 11-20.

López Alonso, F. (1955): "El comienzo de la Edad de los Metales en el noroeste peninsular", Cuadernos de Estudos Galegos, x, pp. 5-41.

Montero, I. y Rovira, S. (1991): "El oro y sus aleaciones en la orfebrería prerromana", Archivo Español de Arqueología, 64, pp. 7-21.

Needham, S. (2013): "Copper daggers and knives". En Fitzpatrick, A. P. (ed.): The Amesbury Archer and the Boscombe Bowmen. Bell Beaker Burials on Boscombe Down, Amesbury, Wiltshire. Wessex. Archaeology Report, 27. Salisbury, pp. 120-129.
Needham, S. y Sheridan, A. (2014): "Chalcolithic and Early Bronze Age goldwork from Britain: new finds and new perspectives". En Meller, H.; Risch, R. y Pernicka, E. (eds.): Metals of power early gold and silver. $6^{\text {th }}$ Archaeological Conference of Central Germany. Halle: Tagungen des Landesmusseums Für Vorgeschichte, 11/II, pp. 903-941.

Perea, A. (1991): Orfebrería prerromana. Arqueología del Oro. Madrid: Caja Madrid-Comun. de Madrid.

Perea, A. (2010): "Arqueología del oro: Tecnología de los metales nobles". En Montero, I. (coord.): $M a-$ nual de Arqueometalurgia. Alcalá de Henares: MAR, pp. 233-268.

Perea, A.; Alguacil, F. J.; Adeva, P. y García-Vuelta, O. (2003): "Contaminación y conservación de piezas de orfebrería prehistórica. ¿Es el oro un metal sin tiempo?", Revista Metal, 39, pp. 3-8.

Perea, A.; García Vuelta, O. y Fernández Freire, C. (2010): El Proyecto Au. Estudio arqueometrico de la producción de oro en la Península Ibérica. Bibliotheca Praehistorica Hispana, Xxvir. Madrid: CsIC.

Perea, A. y Sánchez-Palencia, F. J. (1995a): Arqueología del oro Astur. Oviedo: Caja de Asturias.

Perea, A. y Sánchez-Palencia, F. J. (1995b): "El Oro de los Astures". En Fernández Ochoa, C.: Astures. Gijón, pp. 45-64.

Pernicka, E. (2014): "Possibilities and limitations of provenance studies of ancient silver and gold". En Meller, H.; Risch, R. y Pernicka, E. (eds.): $M e-$ tals of power early gold and silver ( $\sigma^{\text {th }}$ Archaeological Conference of Central Germany). Halle: Tagungen des Landesmusseums Für Vorgeschichte, 11/II, pp. 153-164.

Pop, D.; Ionescu, C.; Forray, F.; Tamas, C. G. y BeNEA, M. (2011): "Transylvanian gold of hydrothermal origin: an EMPA study in an archaeological provenance perspective", European Journal of Mineralogy, 23, pp. 911-923.

Reboredo Canosa, N. (2000): "Evolución tecnológica de la metalurgia del oro, desde el Calcolítico a la Edad del Bronce", Gallaecia, 19, pp. 73-91.

Rovira, S. (2004): "Tecnología metalúrgica y cambio cultural en la prehistoria de la Península Ibérica", Norma, 17, pp. 9-40.

Ruiz Gálvez, M. a L. (1979): "El Bronce Antiguo en la Fachada Atlántica peninsular: un ensayo de periodización", Trabajos de Prehistoria, 36, pp. 151-172.

SÁnchez-Palencia, F. J. (1983): "La explotación prerromana del oro del noroeste de la Península Ibérica", Boletín Auriense, xiII, pp. 31-67. 
Sánchez-Palencia, F. J.; Álvarez, Y. y López, L. F. (1996): "La minería aurífera en Gallaecia". En El oro y la orfebrería prehistórica de Galicia. Lugo: Diput. Prov. Lugo, pp. 9-40.

Standish, C. D.; Dhuime, B.; Hawkesworth, C. J. y Pike, A. W. G. (2015): "A Non-local Source of Irish Chalcolithic and Early Bronze Age Gold”, Proceedings of the Prehistoric Society, 81, pp. 149-177.

Timberlake, S.; Geilt, A. y Davis, M. (2004): “A Cupper Age/Early Bronze Age gold disc from Banc Tynddol (Penguelan, Cwmystwyrh Mines, Ceredigion)", Antiquity, 78 (302), December. https://web. archive.org/web/20060520131721/http://www.antiquity.cc/ProjGall/timberlake/index.html.

Vasilescu, A.; Constantinescu, B. y Bugoi, R. (2011): "Micro-SR-XRF studies of gold provenance in archaeology", Romanian Journal of Physics, 56 (3-4), pp. 366-372.

Vázquez Varela, J. M. (1995): "Etnoarqueología de la eXtracción del oro de los ríos del noroeste de la Península Ibérica", Trabajos de Prehistoria, 52 (2), pp. 157-161.
VilaçA, R. y Pinto. S. (coord.) (2012): Santos Rocha a Arqueología e a Sociedade do seu Tempo. Figuera da Foz.

Villa, L.; Arias, D.; Suárez, O. y Correteé, L. G. (1993): "Distribución y caracterización del oro libre y refractario presente en los filones de cuarzo-arsenopirita de las minas de Penedela, Fornaza y Río de Porcos (Límite entre Lugo y Asturias)", Cadernos do Laboratorio Xeolóxico de Laxe, 18, pp. 81-88.

Waddell, J. (1998): The Prehistoric Archaeology of Ireland. Galway: Galway University Press.

Wood, J. R.; Charlton, M. F.; Murillo, M. y MartiNón, M. (2017): "Gold parting, iridium and provenance of ancient silver: A reply to Pernicka”, Journal of Archaeological Science, 86, pp. 127-130. doi: org/ 10.1016/j.jas.2017.07.005.

Zitnan, P.; Bakos, F. y Schmiderer, A. (2010): “Importance of alluvial gold geochemistry for exploration: Examples from placer in the Western Carpatians", Minerallia Slovakia, 42, pp. 57-68. 